\title{
Synaptic Plasticity and Learning: Selective Impairment of Learning in Rats and Blockade of Long-Term Potentiation in vivo by the N-Methyl-D-Aspartate Receptor Antagonist AP5
}

\author{
R. G. M. Morris \\ Department of Pharmacology, University of Edinburgh Medical School, Edinburgh EH8 9JZ, Scotland
}

\begin{abstract}
This paper reports a series of 5 experiments concerned with a possible role for $\mathrm{N}$-methyl-D-aspartate (NMDA) receptors in certain types of learning. The results show that chronic intraventricular infusion of the NMDA receptor antagonist $D, L-$ 2-amino-5-phosphonopentanoic acid (D,L-AP5) caused an impairment of spatial but not of visual discrimination learning in rats. Such selectivity of the learning impairment occurred despite widespread distribution of the drug throughout the CNS. AP5 sometimes caused a disturbance of sensorimotor function during learning, but one experiment addressing whether this disturbance could be responsible for the spatial learning impairment established that it was statistically independent. Another experiment showed that AP5 did not affect the retention of previously acquired spatial information. These behavioral effects were all obtained with a concentration of AP5 that, in a final study, was found to be sufficient to block hippocampal long-term potentiation (LTP) in vivo without affecting normal synaptic transmission. Taken together, these observations (1) implicate NMDA receptors in certain types of learning, and (2) extend recent work showing that saturation of LTP causes an anterograde spatial amnesia (McNaughton et al., 1986). A preliminary report of parts of this work has been published (Morris et al., 1986a).
\end{abstract}

Excitatory amino acid receptors are commonly divided into 3 types, classified with respect to their preferential activation by kainate, quisqualate, and $N$-methyl-D-aspartate (NMDA) (Watkins and Evans, 1981; Foster and Fagg, 1984; McLennan, 1984; Mayer and Westbrook, 1987). In the hippocampus, activation of the kainate/quisqualate-preferring subtypes by the endogenous transmitter (probably L-glutamate) mediates fast excitatory postsynaptic potentials, but the NMDA subtype has functions that as yet remain unclear (Dingledine, 1986; Cotman and Iversen, 1987). Recent physiological studies indicate that this receptor has the unusual property of becoming active only on depolarization (Dingledine, 1983) due to a voltage-dependent

\footnotetext{
Received Sept. 26, 1988; accepted Nov. 3, 1988.

This work was supported by an MRC Research Fellowship to R.G.M.M. (G83/ $1479 \mathrm{~N}$ ) and largely conducted at the University of St. Andrews. I am indebted to Gary Lynch and Michel Baudry, who first suggested to me the idea of doing behavioral experiments using AP5, and to my colleague Steven Butcher for his work in measuring AP5 levels and for discussion about many aspects of this work. Thanks are also due to Elizabeth Anderson and Robert Halliwell who ran parts of the experiments, and to Frank Schottler, Mary English, Elma Forrest, Bill Dewar, and Chris Barman for their technical assistance.

Correspondence should be addressed to R.G.M. Morris, Department of Pharmacology, University of Edinburgh Medical School, 1, George Square, Edinburgh EH8 9JZ, Scotland.

Copyright (C) 1989 Society for Neuroscience $0270-6474 / 89 / 093040-18 \$ 02.00 / 0$
}

block of the associated ion channel by magnesium (Mayer et al., 1984; Nowak et al., 1984). This intriguing property of NMDA receptors is central to a hypothesis concerning the possible role of these receptors in learning that will be outlined in detail below.

The availability of several potent and selective NMDA receptor antagonists, such as D,L-2-amino-5-phosphonopentanoic acid (D,L-AP5) and other related compounds (e.g., AP7, CPP; see Watkins and Olverman, 1987), has provided the necessary pharmacological tools for understanding many aspects of NMDA receptor action. AP5 blocks depolarization induced by iontophoretic application of NMDA but is without effect on kainateand quisqualate-induced depolarization (Crunelli et al., 1983; Harris et al., 1984). It does not block low-frequency synaptic transmission in hippocampus (Collingridge et al., 1983) unless the concentration is very high (Hablitz and Langmoen, 1986), but low-frequency transmission can sometimes be blocked in other brain areas (Thomson et al., 1985). However, AP5 does block the induction of sustained depolarization by high-frequency stimulation and the propagation of epileptiform discharges in hippocampal slices (Herron et al., 1986). NMDA antagonists are potent muscle relaxants (Turski et al., 1985) and anticonvulsants (Croucher et al., 1982; see Patel et al., 1988) and can also protect neurons against brain damage induced by ischemia (Simon et al., 1984; Meldrum, 1985). Important as these latter observations undoubtedly are, it seems unlikely that the normal function of NMDA receptors is, to borrow Dingledine's (1986) memorable phrase, to "lurk malevolently in the surface membrane, waiting to cause epilepsy." What, then, might be their function?

In this paper, I pursue the hypothesis that hippocampal NMDA receptors play a crucial role in certain types of learning. The first clue to such a role came from a series of studies showing that the highest density of NMDA receptors is in the hippocampus (Olverman et al., 1984; Monaghan and Cotman, 1985) and that AP5 causes a dose-dependent block of the induction of long-term potentiation (LTP) (Bliss and Lomo, 1973) in the in vitro hippocampal slice (Collingridge et al., 1983; Harris et al., 1984). Hippocampal LTP has been implicated in learning on the basis of both theoretical (Swanson et al., 1982; McNaughton, 1983; Lynch and Baudry, 1984; Teyler and DiScenna, 1986) and experimental (Barnes, 1979; Laroche and Bloch, 1982; Berger, 1984; Skelton et al., 1985; McNaughton et al., 1986) studies. The second clue came from studies showing that hippocampal lesions cause selective impairments in certain "declarative" or "representational" memory tasks analogous to those impaired in human amnesia (O'Keefe and Nadel, 1978; Olton et al., 1979; Mishkin, 1982; Squire and Zola-Morgan, 


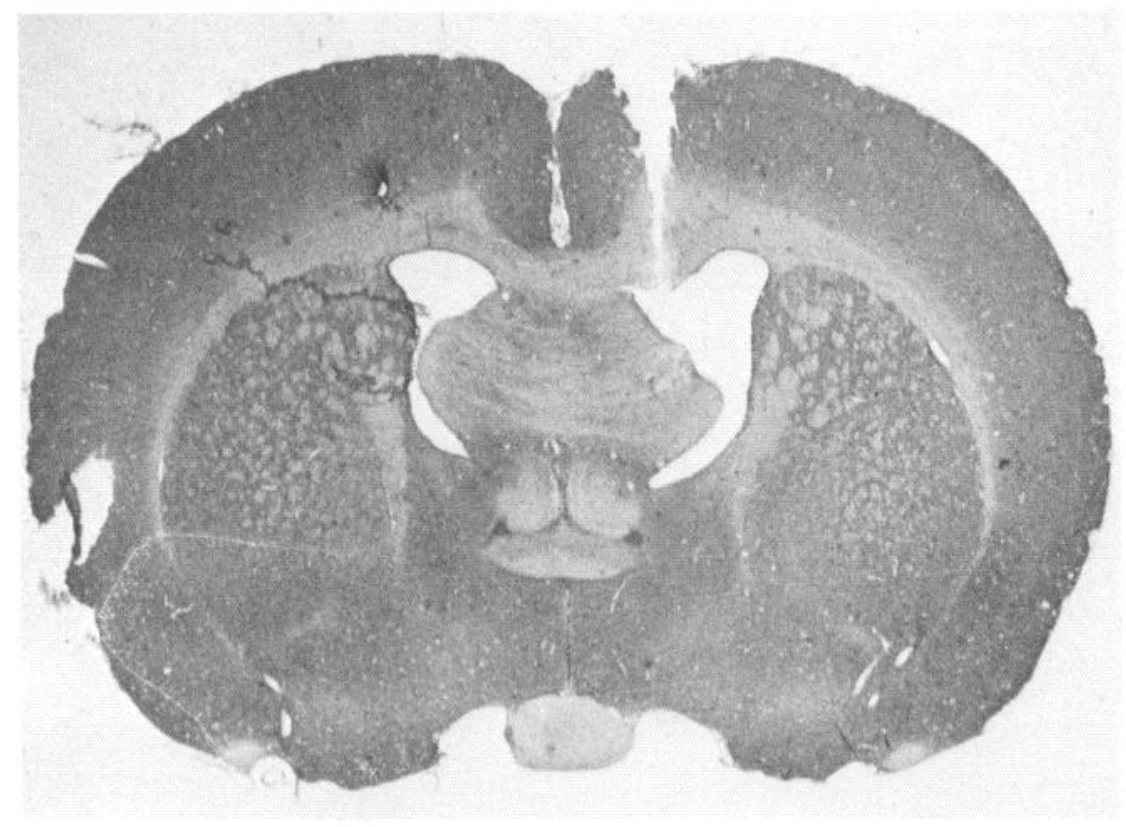

Figure 1. Nissl-stained coronal section showing the typical brain damage caused by the intraventricular cannula (all experiments). In some animals, there was a region of gliosis around the cannula and slight cell damage in the lateral septal region.

1983; Rawlins, 1985; Jarrard, 1986; Squire, 1987). Put together, these facts suggest the following general hypothesis: experiencedependent alterations in synaptic efficacy in hippocampus, triggered by the activation of NMDA receptors, play a crucial role in the processing, storage, or retrieval of information that underlies representational types of memory.

The use of selective NMDA antagonists such as AP5 offers a new avenue for exploring this hypothesis. Specifically, it allows investigation of the behavioral capacities of an animal whose hippocampus and other brain structures are, presumably, functioning normally except for their inability to alter synaptic efficacy in response to experience. The hypothesis makes the important and testable prediction that AP5 should impair a subset of those learning tasks that are impaired by hippocampal lesions but should be without effect on tasks unaffected by such damage. The present series of experiments tests this prediction. The reason that only a subset of the tasks impaired by lesions would be affected is because a proportion of the lesion-impaired tasks will, presumably, involve neural activity in hippocampal circuitry that does not result in or require alterations in synaptic efficacy. A place navigation water task (Morris, 1981) was chosen on the grounds that spatial learning is at least one if not a primary function of the rodent hippocampal formation (O'Keefe and Nadel, 1978) and that this task is exquisitely sensitive to hippocampal lesions (Morris et al., 1982; Sutherland et al., 1983). Furthermore, the task can be easily adapted to study types of learning that are unaffected by hippocampal damage, such as visual discrimination (Morris et al., 1986b).

\section{Materials and Methods}

\section{Subjects}

Each of the experiments used male hooded Lister rats weighing between $235-535 \mathrm{gm}$. They were housed individually in plastic cages with ad libitum access to food and water. A 12-hr light/dark cycle was maintained, with all testing carried out in the light phase ( $8 \mathrm{am}-8 \mathrm{pm})$. All rats were well handled prior to experimentation.

\section{Apparatus}

Behavioral studies. The rats were trained in a large swimming pool (2.1 $\mathrm{m}$ diameter, $0.6 \mathrm{~m}$ high) containing water at $26 \pm 1^{\circ} \mathrm{C}$ made opaque by the addition of dry powdered milk. The pool was in the center of a large laboratory containing various prominent cues (metal filing cabinet, section of primate caging, posters on the walls and door).

For the spatial learning tasks, a 10-cm-diameter escape platform was hidden at any of 4 positions in the pool (arbitrarily designated SW, NW, $\mathrm{NE}$, and SE) exactly $50 \mathrm{~cm}$ from the side walls. Its top surface was 1.0 $1.5 \mathrm{~cm}$ below the water level. The platform was visible when viewed from directly above but was invisible when viewed from along the water surface. A video camera was mounted to the ceiling above the pool and connected to a video recorder and tracking device (HVS Image Analysing Ltd., Kingston, UK) that allowed on- and off-line automated tracking of the path taken by the black head of the otherwise white rat (see Morris, 1984). The resulting $x$ and $y$ coordinates were digitized at $10 \mathrm{~Hz}$ by a BBC microcomputer and subsequently stored on disk. In this way, it was possible to get objective measures of the paths taken by the rats as they searched for the platform (e.g., latency to escape, distance, position in the pool). However, the tracking system was used only on selected trials (e.g., final few trials of training and transfer tests). At other times, escape latency was measured using a stopwatch. For nonspatial learning, the perimeter of the pool was completely surrounded by black curtains, which occluded sight of the extramaze cues, and the platform was moved from place to place between trials. For the visual discrimination task, 2 visible platforms were present. They were $10 \mathrm{~cm}$ in diameter and protruded out of the water by $1.0-1.5 \mathrm{~cm}$. One was painted gray, the other with vertical black and white stripes. One of the platforms (either gray or striped) was rigid and offered escape from the water. The other (striped or gray, respectively) was floating such that when the rats attempted to get onto this platform, they immediately fell back into the water (the platform was filled with expanded polystyrene). Normal rats quickly grasp the "logic" of the situation and learn to swim preferentially to the rigid platform on successive trials. The black curtains surrounded the perimeter of the pool throughout this task to minimize the influence of extramaze cues.

Electrophysiological study. Perforant path-evoked field potentials were recorded from the dentate gyrus of urethane-anesthetized $(1.5 \mathrm{gm} / \mathrm{kg})$ rats mounted in a Kopf stereotaxic frame. A teflon-coated bipolar stimulating electrode (Medwire $110 \mu \mathrm{m}$ ) was lowered into the perforant path at approximately $7.6 \mathrm{~m}$ posterior to bregma, $4.0 \mathrm{~mm}$ lateral to the midline and $2.0-2.5 \mathrm{~mm}$ ventral to the brain surface. A bipolar recording 


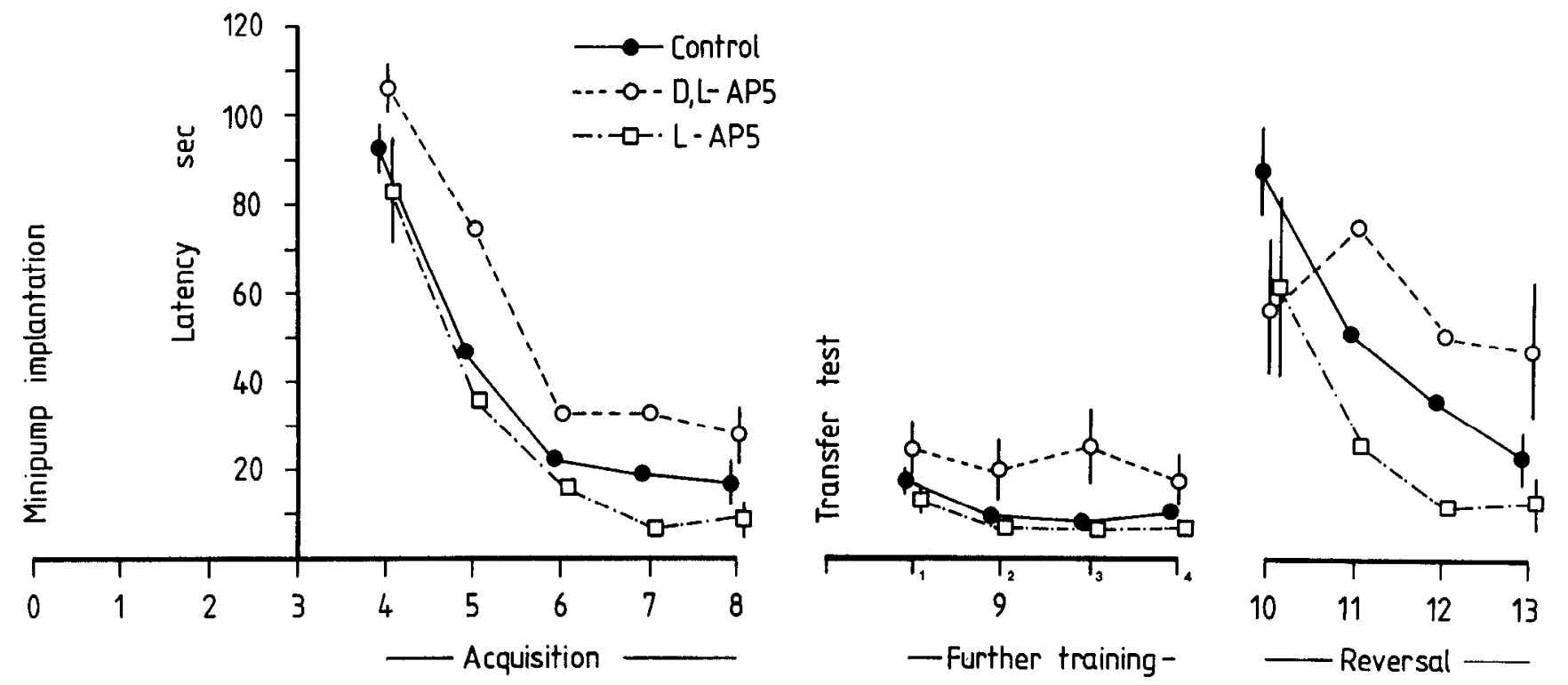

Figure 2. Experiment 1. Mean latency of escape (sec \pm 1 SEM) for each of the $10 \mathrm{~d}$ of behavioral testing. Phase $1=$ days 4-8; phase $2=$ day 9 ; phase 3 = days 10-13. Note the partial impairment of the D,L-AP5 group in phase 1 and the sustained deficit of phases 2 and 3 .

electrode pair with vertically staggered tips was lowered into the dentate hilus of the dorsal hippocampus [Anterior/Posterior (AP), $-3.5 \mathrm{~mm}$; lateral, $1.8 \mathrm{~mm}$; ventral, $2.8-3.2 \mathrm{~mm}$ ] such as to record both hilus(positive-going) and molecular-layer- (negative-going) evoked potentials. The ventral locations of both stimulating and recording electrodes were adjusted to maximize the size of the hilus potentials (the only ones measured quantitatively). The detailed protocol for stimulation and recording is given below.

\section{Surgery, drug concentrations, histology, and drug diffusion}

Surgery. As AP5 does not cross the blood-brain barrier, it was chronically infused into the brain via surgically implanted osmotic minipumps. On a day referred to as day 0 of each experiment, the rats were anesthetized with tribromethanol (Avertin) and placed into a Kopf stereotaxic instrument. An L-shaped stainless-steel cannula (25 gauge) was lowered into the right lateral ventricle (AP from bregma $-0.9 \mathrm{~mm}$; lateral, $1.3 \mathrm{~mm}$; ventral, $-4.5 \mathrm{~mm}$ from skull surface) and secured by means of dental cement and small skull screws. Silicone rubber tubing connected the cannula to an Alza minipump (Model 2002; pumping rate $=0.5 \mu 1 / \mathrm{hr}$ ), which was then implanted subcutaneously. The rats were always allowed at least $3 \mathrm{~d}$ to recover from the acute effects of surgery and to allow the intraventricular concentration of drugs to reach steady state before starting the next stage of each experiment.

Drug concentration. Rats were randomly assigned to groups distinguished with respect to the contents of the minipumps. In experiments 1,2 , and 5 , the drugs were dissolved in $0.9 \%$ saline; artificial cerebrospinal fluid (aCSF) was used in experiments 3 and 4 (Urquhart et al., 1984). D,L-AP5 was made up at a concentration of $40 \mathrm{~mm}$. This resulted in an intracerebral infusion rate of $20 \mathrm{nM}$ of AP5 per hour. The estimated cerebrospinal fluid exchange rate for the rat is $2.2 \mu \mathrm{l} / \mathrm{hr}$ (Bass and Lundborg, 1973). Assuming that none of the AP5 that escapes the cerebrospinal fluid into the blood reenters the brain, the cerebral concentration of AP5 should stabilize at approximately $150 \mu \mathrm{M}$, i.e., a value approximately 3 times higher than that required to block LTP in vitro (Harris et al., 1984). I-APV was made up at a concentration of $20 \mathrm{~mm}$ because D,L-AP5 is known to contain equal amounts of the 2 racemates of AP5.

Histology. At the end of all but one experiment, the rats were deeply anesthetized with Euthatal and perfused transcardially with isotonic saline and $10 \%$ formalin. The brains were removed, sectioned in the coronal plane throughout the region of the cannula placements $(40 \mu \mathrm{m}$ sections), and stained with cresyl violet. The sections were assessed with respect to (1) whether the cannula had entered the lateral ventricle (Fig. 1) and (2) brain damage. The numbers per group given below refer to rats accepted into any experiment (rats being rejected if there was doubt about the cannula placement or unacceptable brain damage).
Drug diffusion. At the end of experiment 3, the animals were killed by stunning and the brains quickly removed. A thin coronal section including the region of the cannula placement was placed in formalin for later histological analysis. Samples of the left and right hippocampus, visual cortex, and, in some animals, striatum and frontal cortex were dissected, weighed, and placed in a $0.6 \mathrm{~m}$ solution of perchloric acid, and frozen. Later, AP5 was separated from other primary amines by reverse-phase high pressure liquid chromatography (HPLC) and detected as a fluorescent derivative following precolumn derivatization with o-pthaldialdehyde. Separation was achieved using a gradient elution system: buffer A: $50 \mathrm{~mm}$ phosphate buffer ( $\mathrm{pH} \mathrm{5.12)}$ containing $2.5 \%$ tetrahydrofuran; buffer $\mathrm{B}$ : methanol containing $1.25 \%$ tetrahydrofuran; gradient [time (min): $\%$ A; $\% \mathrm{~B}], 0,100,0 ; 3,100,0 ; 10 ; 70 ; 30$; 20,$42 ; 58 ; 26,0,100 ; 36,100,0$ (S. P. Butcher, R. G. M. Morris, and A. Hamburger, unpublished observations).

\section{Experiment 1: does AP5 impair spatial learning? \\ Purpose}

The purpose of the first experiment was to investigate whether AP5 would impair the acquisition and reversal of place navigation in the water maze.

\section{Procedure}

Four groups of rats (D,L-AP5, $n=10$; L-AP5, $n=6$; saline, $n$ $=10$; unoperated, $n=10$ ) were given the same behavioral training procedures divided into 3 phases as follows.

In phase $I$ (days 4-8, measured in terms of days since the surgical implantation of the minipumps on day 0 ), the rats were given a total of 15 training trials [ 3 trials $/ \mathrm{d}, 4 \mathrm{hr}$ intertrial interval (ITI)]. On each trial, a rat was placed into the pool at any one of 4 possible starting points at the perimeter of the pool and allowed to swim until it found and climbed onto the escape platform. It was left there for $30 \mathrm{sec}$ and then returned to its home cage. If the rat failed to find the platform within $120 \mathrm{sec}$, it was placed onto it by hand. Escape latency was measured with a stopwatch.

Phase 2 (day 9) consisted of a single spatial transfer test followed immediately by 8 further training trials. The purpose of the transfer test was to find out how much had been learned about the location of the escape platform. To do this, the plat- 
Saline 2131

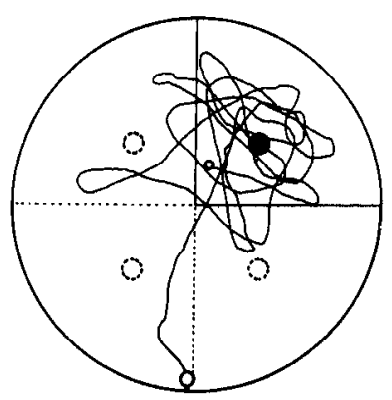

Unop + Sal
D,L-APS

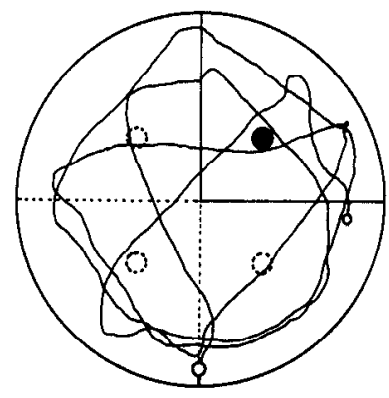

D,L- APS

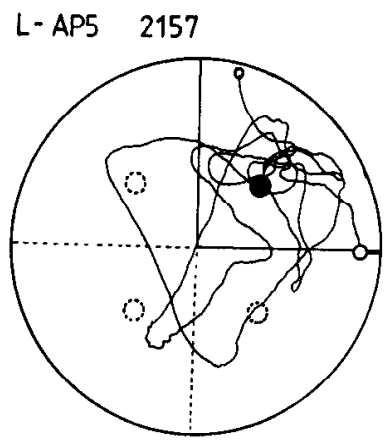

L-AP5

$N=6$

.
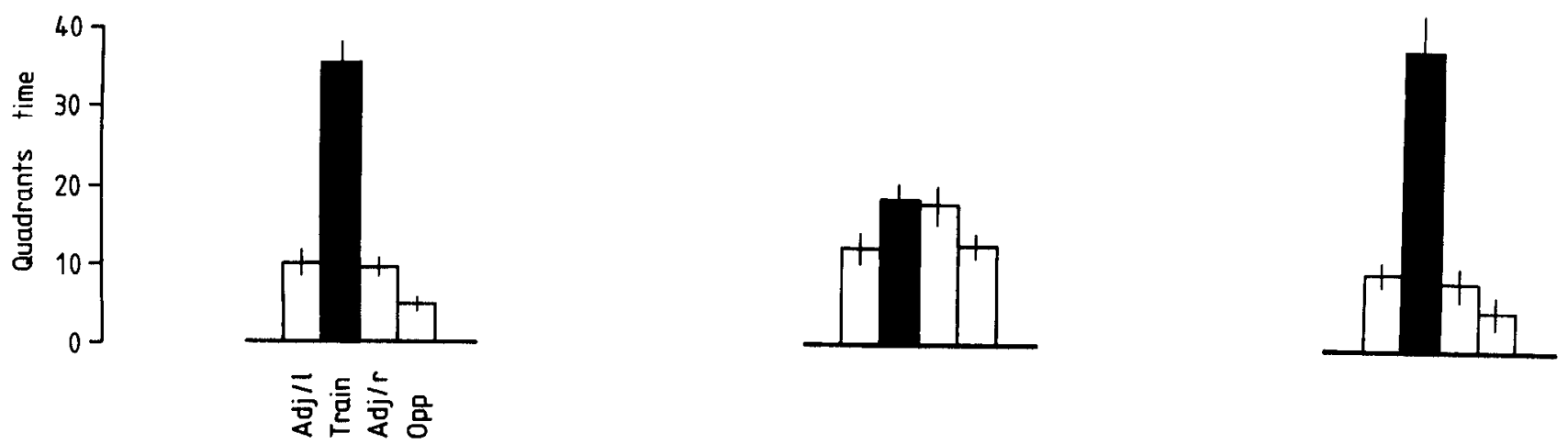
tween groups was maintained $(F=7.87$, df $2 / 33, p<0.002)$ with the impairment again restricted to the D,L-AP5 group (D,LAP5 vs control, $p<0.0005$; see Fig. 2, Further Training). Whereas control and L-AP5 rats appeared to take rapid, direct paths to the platform on most trials, the D,L-AP5 group was inconsistent: some rats were consistently poor, giving no evidence of having learned where the hidden platform was located; others sometimes escaped rapidly although their paths were never very direct. These differences in the apparent directionality of approach to the platform are analyzed more thoroughly in subsequent experiments.

The start of phase 3 (reversal) was characterized by an increase in escape latency on the first trial in all groups, with a trend towards a smaller increase in the D,L-AP5 rats (control increased by $75.3 \mathrm{sec}, \mathrm{L}-\mathrm{AP} 5$ by $53.4 \mathrm{scc}$, and D,L-AP 5 by $34.9 \mathrm{scc} ; 0.10$ $>p>0.05$ ). The overall analysis of the reversal trials showed an impairment across groups $(F=7.68$, df $2 / 33, p<0.005)$. The D,L-AP5 group showed little improvement across trials, while both the control and L-AP5 rats showed steady reductions in escape latency. However, the groups $\times$ trials interaction did not reach significance $(F=1.52, p>0.10)$.

The most striking impairment in the D,L-AP5 group was observed during the transfer test of phase 2 (Fig. 3). While control and L-AP5 rats showed a pronounced spatial bias towards the training quadrant, D,L-AP5 rats showed little indication of having learned anything about the platform's location. An analysis of variance of the quadrant times scores revealed a highly significant groups $\times$ quadrants interaction $(F=8.62, d f 4 / 99, p<$ 0.0001 ; numerator $d f$ decreased as quadrant times necessarily add to $60 \mathrm{sec}$, as in Morris, 1981). Figure 3 indicates that this interaction was due to the relatively uniform distribution of time spent around the pool by the D,L-AP5 group relative to the other 2 groups.

A final point about the performance of the rats should be noted. During the course of training, the experimenters (E. A. and R. M.) noticed that on some early training trials (days 47), D,L-AP5 rats fell off the escape platform after having first escaped from the water. Strictly qualitative observations indicated that the rats fell off immediately after doing a "wet-dog" body shake, losing grip of the platform with their hind paws. On a few trials, the rats appeared to "swim off" the platform. They usually got back onto the platform immediately, but occasionally they fell into the water pointing away from the platform, started swimming away, and so failed to find it again immediately. In these cases, the rats were returned to the platform by hand. Rats in the other groups fell off very infrequently. $\Lambda$ s this phenomenon was totally unexpected, no quantitative observations were made at this stage (e.g., the frequency of falls).

\section{Discussion}

These data indicate that intraventricular infusion of D,L-AP5, but not of L-AP5, caused an impairment in place navigation similar to but less severe than that caused by hippocampal lesions (Morris et al., 1982; Sutherland et al., 1983). The impairment occurred in each phase of the experiment and was reflected in 2 independent measures of performance (escape latency and spatial bias). The simplest interpretation of these results is that AP5 has caused an impairment in learning by virtue of blocking experience-dependent alterations in synaptic efficacy within the hippocampus. However, other interpretations of the results are clearly possible.

One possibility is that the performance impairment was caused by a drug-induced effect on motivation or reinforcement-the AP5 rats were either not motivated to escape from water or felt less rewarded for doing so. Another possibility is that the apparent learning impairment was a secondary consequence of the sensorimotor disturbance. For example, a rat that found the hidden platform but was unable to stay on it effectively might have come to regard the platform as an unrewarding refuge. Learning would have then proceeded more slowly, not because of any direct effect of AP5 on either reinforcement or learning processes themselves but because the animal's own behavior had rendered the nominal reward functionally less effective. Experiments 2, 3, and 4 of this series are an attempt to dissociate these possibilities.

The unexpected sensorimotor disturbance induced by $D, L-$ AP5 appcarcd to arise partly from a disruption of the suprasegmental spinal reflexes that maintain an upright body posture during a "wet-dog" shake (high-speed films reveal that during "wet-dog" shaking the anterior and posterior parts of an animal's body are instantaneously rotating in opposite directions around the longitudinal body axis). The falling-over phenomenon occasionally occurred in the home cage where rats frequently attempt to shake of any remaining water from their fur after immersion in the pool. As intrathecal administration of AP5 induces a similar but more severe sensorimotor disturbance (Cahusac et al., 1984), it is possible that chronic intraventricular infusion of AP5 also antagonizes NMDA receptors involved in polysynaptic excitation of ventral horn neurons of the spinal cord (Davies and Watkins, 1983). However, the phenomenon may also be due to more central actions of the drug. AP5 blocks unit activity in the ventrobasal thalamus evoked in response to natural stimulation of the vibrissae (Salt, 1986). Thus, the D,LAP5 rats may have had difficulty in gripping the platform because of some somatosensory dysfunction. A further point is that some D,L-AP5 rats were "flaccid" (i.e., they lacked muscle tone), and Klockgether et al. (1986) have shown that the muscle relaxant effects of AP5 may also be mediated by NMDA receptors in the ventrobasal thalamus.

Strangely, the sensorimotor disturbance did not occur in every animal nor even in all rats that showed the most pronounced impairment of learning. It declined across days and rarely occurred during the later stages of training. This suggests that the learning impairment and the sensorimotor disturbance may indeed depend on different sites of action of AP5 in the CNS and thus be behaviorally independent. In the following 3 experiments, various strategies were pursued in an effort to dissociate these differing explanations for the behavioral effects of AP5 in the place navigation task. Experiment 2 examined the effects of AP5 on a type of learning known to be unaffected by hippocampal lesions. Experiment 3 attempted to manipulate the sensorimotor disturbance independently of any effect that AP5 might be having on learning. Experiment 4 examined the effect of AP5 on the retention of spatial information learned prior to drug infusion.

\section{Experiment 2: does AP5 impair visual discrimination learning?}

\section{Purpose}

One of the cardinal features of most efforts to construct animal models of amnesia over the past 15 years has been the desire to demonstrate a dissociation between types of learning impaired by hippocampal damage (or hippocampal and amygdala 
lesions; see Mishkin and Petri, 1984) and types of learning that are unaffected by such damage. Different theorists capture the distinction between spared and impaired function in different ways, and this is reflected in the types of memory paradigms that are studied. However, while there is much disagreement as to the theoretical basis for the dissociation (see Weiskrantz, 1982), it is widely agreed that spatial learning tasks are, in general, impaired by hippocampal lesions, while visual discrimination tasks are not (e.g., O'Keefe and Nadel, 1978; Mishkin, 1982; Squire and Zola-Morgan, 1983). For present purposes, a crucial issue is whether AP5 impairs visual discrimination learning as well as spatial learning.

A second reason for interest in visual discrimination learning is that NMDA receptors have been implicated in cortical plasticity responsible for the maintenance of ocular dominance and orientation selectivity (Kleinschmidt et al., 1987; Bear et al., 1987; Singer, 1987). While these types of plasticity are very different from spatial learning, and indeed from visual discrimination learning, it seems likely that NMDA receptors play some general role in detecting the conjunction of pre- and postsynaptic neural activity. The particular role of NMDA receptors in learning will then be critically dependent on the neural architecture within which they are embedded.

Assume for the moment that chronic intraventricular infusion of AP5 results in its relatively wide distribution all over the brain, including areas such as the lateral geniculate nucleus and visual cortex which have been implicated in visual discrimination learning (Thompson, 1976). The finding of an impairment of visual discrimination learning would imply either (1) that NMDA receptors outside the hippocampus are involved in this and other "nonhippocampal" types of learning, or (2) that both it and the place navigation impairment are artifacts of the sensorimotor disturbance induced by AP5. On the other hand, the lack of any AP5-induced impairment of visual discrimination would imply (1) that the sensorimotor disturbance account of the place navigation impairment is unlikely because there is no obvious reason why such a disturbance should affect one type of learning but not another (particularly another making broadly similar sensory and motor demands upon the animal), and (2) that hippocampal NMDA receptors are the major site of action for intraventricular AP5.

\section{Procedure}

Four groups of rats (D,L-AP5, $n=13$; L-AP5, $n=9$; saline, $n$ $=7$; unoperated, $n=6$ ) were, following surgery, given visual discrimination training as follows.

All rats were given 10 trials/d, for up to a total of $12 \mathrm{~d}$ (by which time the minipumps were exhausted), to discriminate the rigid from the floating visible platform. On each trial, the platforms were placed in any of 8 possible locations, subject to the restriction that the correct (rigid) platform was as often on the left of any starting position as on the right. The 2 platforms were typically equidistant from the start (approximately 6 trials/ d), with the rigid platform being the closer to the start on 2 trials and the one farther away on the remaining 2 trials/d. The rats were put into the water, facing the side walls, at any of 8 possible starting locations around the perimeter of the pool. They were trained until they reached the strict criterion of 9 successive correct responses during a single 10-trial session, a correct response being defined as preferential approach to the rigid platform without touching the floating one.

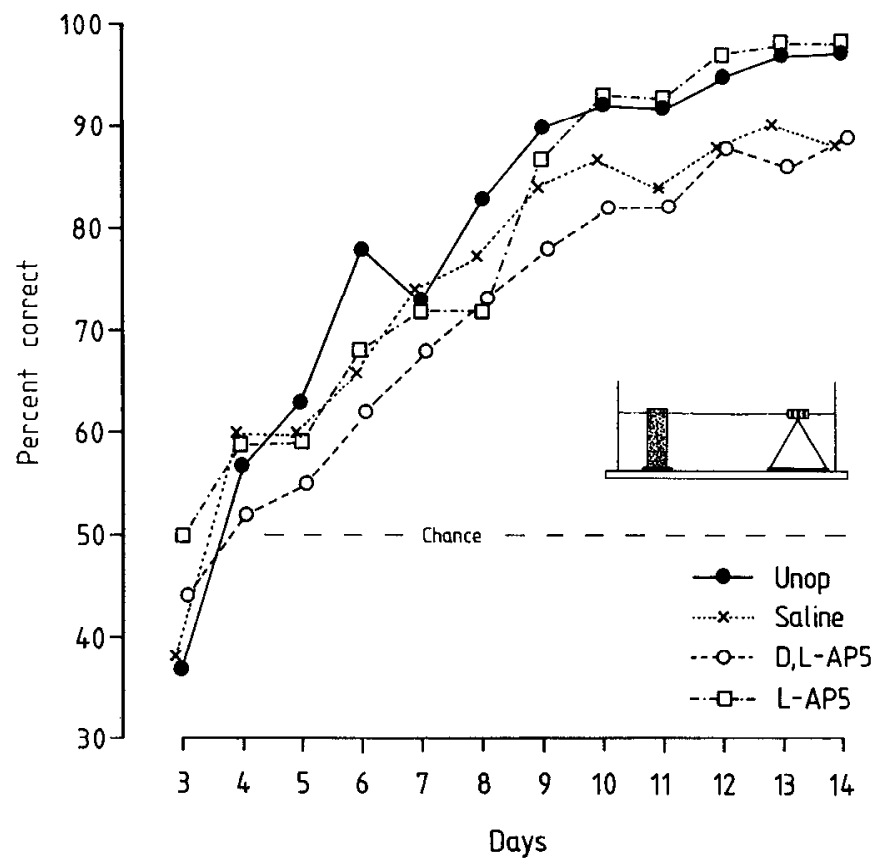

Figure 4. Experiment 2. Mean learning curves for the 2-platform visual discrimination task over the $12 \mathrm{~d}$ of training. All groups learned the task effectively, and there was no difference between AP5 rats and controls.

\section{Results}

The main finding of this experiment was that AP5 caused no detectable impairment of visual discrimination lcarning (Fig. 4). A second finding was that the AP5 rats did not show any sensorimotor abnormalities on the platform at any point during the experiment.

All rats learned the visual discrimination task to some level of proficiency. Initially (i.e., approximately the first 5 trials) the rats "wrestled" with the floating platform when they touched it. They soon learned to swim away from the floating platform immediately on contact but only began to avoid contacting it altogether later. Sometimes the "decision" to avoid the floating platform appeared to be made quite close to it (within 5 to 10 $\mathrm{cm}$ swimming distance), whereas on other trials the animals would briefly stop swimming on the opposite side of the pool, scan the 2 platforms, and then swim directly for the rigid one. On many trials there was no obvious "decision point," and I was unable to make any analysis of their behavior other than the usual measure (for discrimination tasks) of number of trials correct per day.

Figure 4 shows the mean percentage correct over the $12 \mathrm{~d}$ of training. An unequal $n$ analysis of variance conducted on the arcsine transformed choice data showed no difference between groups $(F<1)$. There was a steady improvement in choice performance across days $(F=52.3, p<0.0001)$ but no interaction between groups and days $(F<1)$. Most animals $(30 / 35)$ reached the stringent learning criterion of 9 successive correct response in a 10-trial session. A nonparametric analysis of trials to criterion showed no significant difference between groups (Kruskal-Wallis $H=7.19, p>0.05$ ).

\section{Discussion}

The results of this experiment show that AP5 does not impair visual discrimination learning and need not cause the sensori- 
motor impairment observed in some animals during experiment 1. These findings indicate that intraventricular infusion of AP5 does not affect motivation or reinforcement processes, and they stand in contrast to the AP5-induced blockade of ocular dominance shifts after reverse eye suturing (Kleinschmidt et al., 1987). They suggest the simple idea that $N M D A$ receptors are not involved in all types of learning.

However, it should be noted (1) that a learning impairment was found in association with a sensorimotor disturbance in experiment 1 but both effects were absent in this experiment. Furthermore, the assertion that activation of NMDA receptors is not required for all types of learning rests on the assumption, stated above, that (2) intraventricular infusion does result in widespread diffusion of AP5 all over the brain. In making this very criticism, Goddard (1986) wondered whether the apparent dissociation between types of learning induced by intraventricular infusion of AP5 reflected anything more than differential drug distribution through the brain. Both issues (1) and (2) are addressed in experiment 3.

\section{Experiment 3: can the sensorimotor disturbance be dissociated from the spatial learning impairment? \\ Purpose}

The drug-induced sensorimotor disturbance of experiment 1 may give rise to an apparent impairment of place learning because the animals' inability to use the escape platform effectively makes it a functionally less effective refuge. The animals might then search for an alternative route of escape and so display longer escape latencies during training, a lack of bias to the platform quadrant during the transfer test, and so on. There are 2 ways of addressing this problem.

One way would be to train the animals in the absence of AP5 (phase 1) and to start to administer the drug only after they have learned the task (phase 2). This experimental design suffers from the disadvantage that a clear interpretation is possible only if the drug affects either learning or sensorimotor function but not if it affects both functions (because the presence of an impairment in phase 2 would not necessarily imply that NMDA receptors are not also involved in learning). This design is in fact used in experiment 4 , but to be interpretable, a different kind of experiment had to be done first.

That expcriment, indecd the second way to address the sensorimotor problem, was to try to separate the phase of training when the rats are learning to search for, use, and stand on the hidden platform ("use of platform" learning) from the phase when the rats are learning its location in space ("spatial learning"). Ordinarily, these 2 aspects of learning are co-occurrent. The essential feature of experiment 3 was therefore to arrange for these different lypes of learning to occur in series, the former in the absence of AP5 and the latter in its presence. Animals that have learned to use the platform in the absence of AP5 should show a substantially diminished sensorimotor disturbance in the later phase of training. Moreover, if these animals continue to display a severe impairment of spatial learning, it would indicate that NMDA receptors do indeed participate in some important way in the learning process itself.

A second aim of experiment 3 was to examine the intracerebral distribution of AP5 in different areas of the brain. The main result will be reported, but the procedural details, effects of AP5 administration on other excitatory amino acids, and other details are reported elsewhere (Butcher et al., unpublished obser- vations), as they are not directly germane to the central aim of this paper.

\section{Procedure}

Four groups of rats [pretrained D,L-AP5, $n=5$; pretrained control, $n=8$ (aCSF, $n=4$; unoperated, $n=4$ ); posttrained D,LAP5, $n=7$; posttrained control, $n=14$ (aCSF, $n=7$; unoperated, $n=7$ )] were trained over 2 main phases (separated by surgery) as follows.

In phase 1 ("pretraining" phase: days -4 to -1 , measured in terms of days from subsequent surgery), the pretraining rats ( $n=13$ above) were trained to escape from water onto a platform according to the nonspatial learning protocol $(3$ trials/d, $4 \mathrm{hr}$ ITI, black curtains, platform moved between trials).

In phase 2 ("posttraining" phase: days 4 to 9), all 34 rats were given place navigation training according to an identical spatial learning protocol as that used during experiment 1 . Measures of escape latency during training and the paths taken during the transfer test were recorded as before. Behavior on the platform during phase 2 was monitored using a separate video camera system. The resulting tapes were analyzed to record the number of occasions that rats had an unsteady gait on the platform (this being defined conservatively as loss of grip by at least 1 hind paw and inclusive of both falls and occasions when the rats did not completely fall off the platform).

Following completion of all behavioral procedures, the rats were killed and the brains rapidly removed for dissection on ice ( $10 \mathrm{~d}$ after pump implantation for pretrained rats, $14 \mathrm{~d}$ for posttrained-only rats). Samples of brain tissue for histology and HPLC analysis were taken as described in Materials and Methods.

\section{Results}

The main finding of this experiment was a dissociation between the sensorimotor and learning impairments induced by AP5. In addition, the biochemical observations indicated that although AP5 concentration tended to be highest in the hippocampus, it was widely distributed in all parts of the brain measured.

Behavior on the platform. The videotapes of behavior during phase 2 showed that all animals turned, reared, face-washed and executed the typical "wet-dog" shaking characteristic of rats performing the water escape task. The turning and rearing, so characteristic of rats when they first attempt to learn the position of the hidden escape platform (Sutherland and Dyck, 1984), was apparent in both AP5s and controls. Table 1 shows the mean number of occasions that rats showed motor disturbances on the platform during the 15 acquisition trials of postsurgery spatial training. Pretraining almost totally prevented the AP5-induced sensorimotor impairment. Control rats occasionally fell off the platform, but these falls were largely restricted to the first day of spatial posttraining. Mann-Whitney $U$-tests, for which the rats were ranked according to their total number of motor disturbances, showed that the posttrained AP5 group was significantly more disturbed than the respective controls $(U=5$, $n 1=8, n 2=14, p<0.005$ ). Pretrained AP5 rats were either disturbed or fell off more often than their respective controls on the first day of posttraining $(U=5, n 1=5, n 2=8, p<$ 0.05 ) but never thereafter.

Spatial learning. The performance of the AP5 rats during spatial training was, relative to their appropriate controls, unaffected by pretraining (Fig. 5). Of course, all pretrained rats 


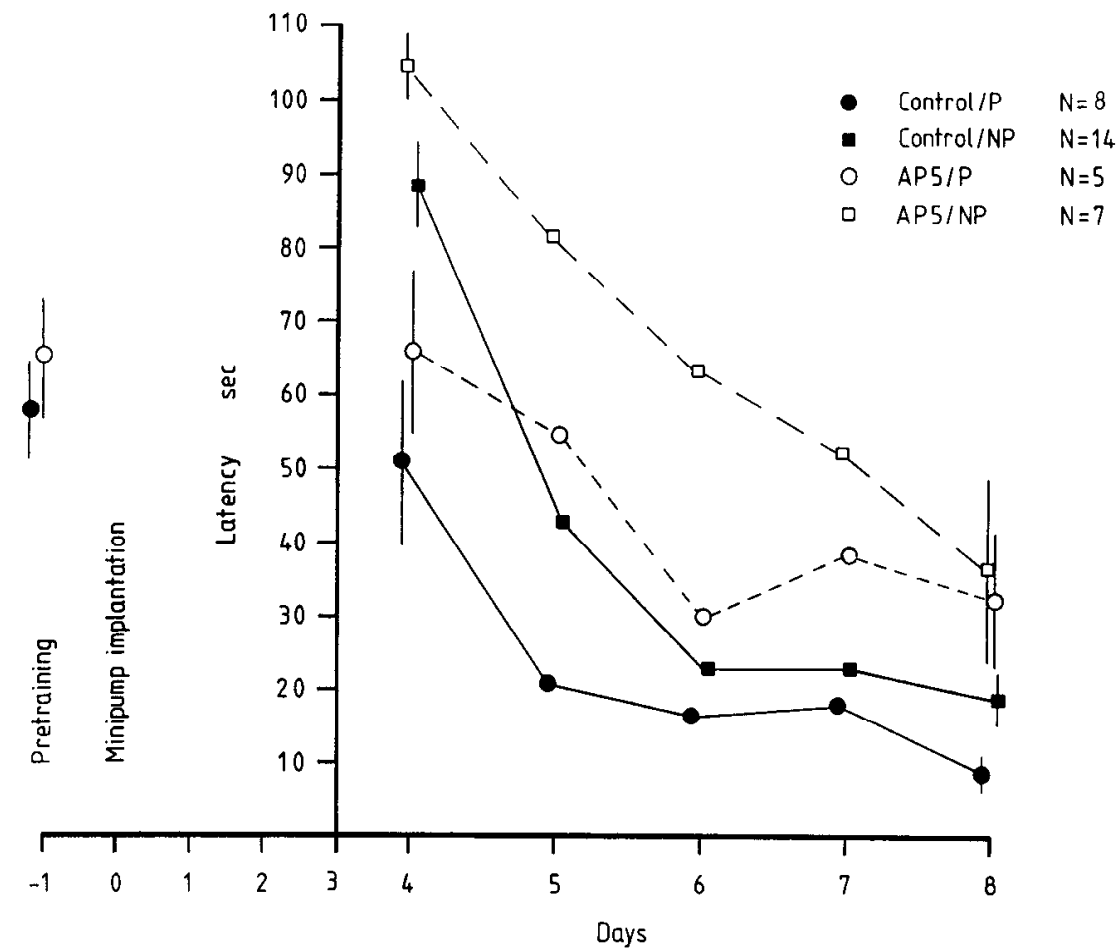

Figure 5. Experiment 3. Mean latency of escape ( $\mathrm{sec} \pm 1 \mathrm{SEM}$ ) for the last day of preoperative training $(-1)$ and each of the $5 \mathrm{~d}$ of postoperative training. Phase $1=$ days -4 to -1 ; phase $2=$ days 4 to 8 . Note that pretraining improved the escape latencies of both the control and the AP5 groups at the beginning of postoperative training (day 4) but that there was little residual effect of pretraining by the end of phase 2 (day 8).
(AP5s and controls) escaped faster at the start of phase 2 training-such was to be expected of animals that had already learned the "nonspecific" requirements of the task during phase 1 (such as use of the platform as a refuge). But the final level of escape performance (day 8) was determined solely by the assignment of drug groups. An overall analysis of variance of the escape latencies across the 15 trials of posttraining revealed significant main effects of group (AP5 vs control: $F=23.5$, df $1 / 30, p<$ $0.0001)$ and pretraining $(F=15.4, d f 1 / 30, p<0.0005)$ thatimportantly - did not interact $(F<1)$. The pretraining $\times$ days interaction was, however, highly significant $(F=5.1, d f 4 / 120$, $p<0.001$ ), indicative of the declining influence of pretraining on escape latency as spatial learning proceeded.

Figure 6 (right-hand side) shows the paths taken during the transfer test by the median rat in the control and AP5 groups, illustrating the impairment in spatial learning induced by AP5. A further striking feature of the transfer test performance (Fig. 6 , left-hand side) is the similarity of the performance of pretrained and nonpretrained rats. An overall analysis of the quadrant times measure (Fig. 6, top row) showed no interaction between pretraining and several other factors-groups, quadrants, and groups $\times$ quadrants (all $F \mathrm{~s}<1$ )-whereas the important groups $\times$ quadrants interaction term, indicative of a drug effect, was highly significant $(F=13.5$, df $2 / 90, p<0.0001$; numerator $d f$ reduced by 1 ). Figure 6 (bottom row) also shows the mean number of times rats crossed the exact former location of the platform as well as 3 other areas in corresponding positions in the remaining cardinal quadrants of the pool. This annulus-crossings score is a measure of the acuity of spatial memory-how well the rats can remember exactly where the platform was located. Control rats crossed the correct location frequently during the $60 \mathrm{sec}$ test - an average of 8.5 times more often than the 3 other corresponding locations. AP5 rats crossed the correct location only 1.5 times more often than the other places. A formal analysis of annulus crossings revealed exactly the same picture as in the quadrants analysis: none of the terms involving the pretraining factor were significant $(F \mathrm{~s}<1)$, whereas the groups $\times$ annulus-position interaction was highly significant $(F=9.2$, df $3 / 90, p<0.0001)$.

Automated tracking of the animals during the transfer test

Table 1. Number of sensorimotor disturbances per trial ( $\pm 1 \mathrm{SEM})$ over the $5 \mathrm{~d}$ of spatial posttraining

\begin{tabular}{|c|c|c|c|c|c|}
\hline \multirow[b]{2}{*}{ Group } & \multicolumn{5}{|c|}{ Postoperative day } \\
\hline & 3 & 4 & 5 & 6 & 7 \\
\hline \multicolumn{6}{|c|}{ Posttrained only } \\
\hline Control & $0.6 \pm 0.2$ & 0.0 & $0.02 \pm 0.0$ & 0.0 & 0.0 \\
\hline AP5 & $2.4 \pm 0.5$ & $1.1 \pm 0.5$ & $0.4 \pm 0.1$ & $0.4 \pm 0.1$ & $0.6 \pm 0.3$ \\
\hline \multicolumn{6}{|l|}{ Pretrained } \\
\hline Control & $0.3 \pm 0.1$ & $0.1 \pm 0.1$ & 0.0 & 0.0 & 0.0 \\
\hline AP5 & $1.3 \pm 0.4$ & 0.0 & 0.0 & 0.0 & 0.0 \\
\hline
\end{tabular}



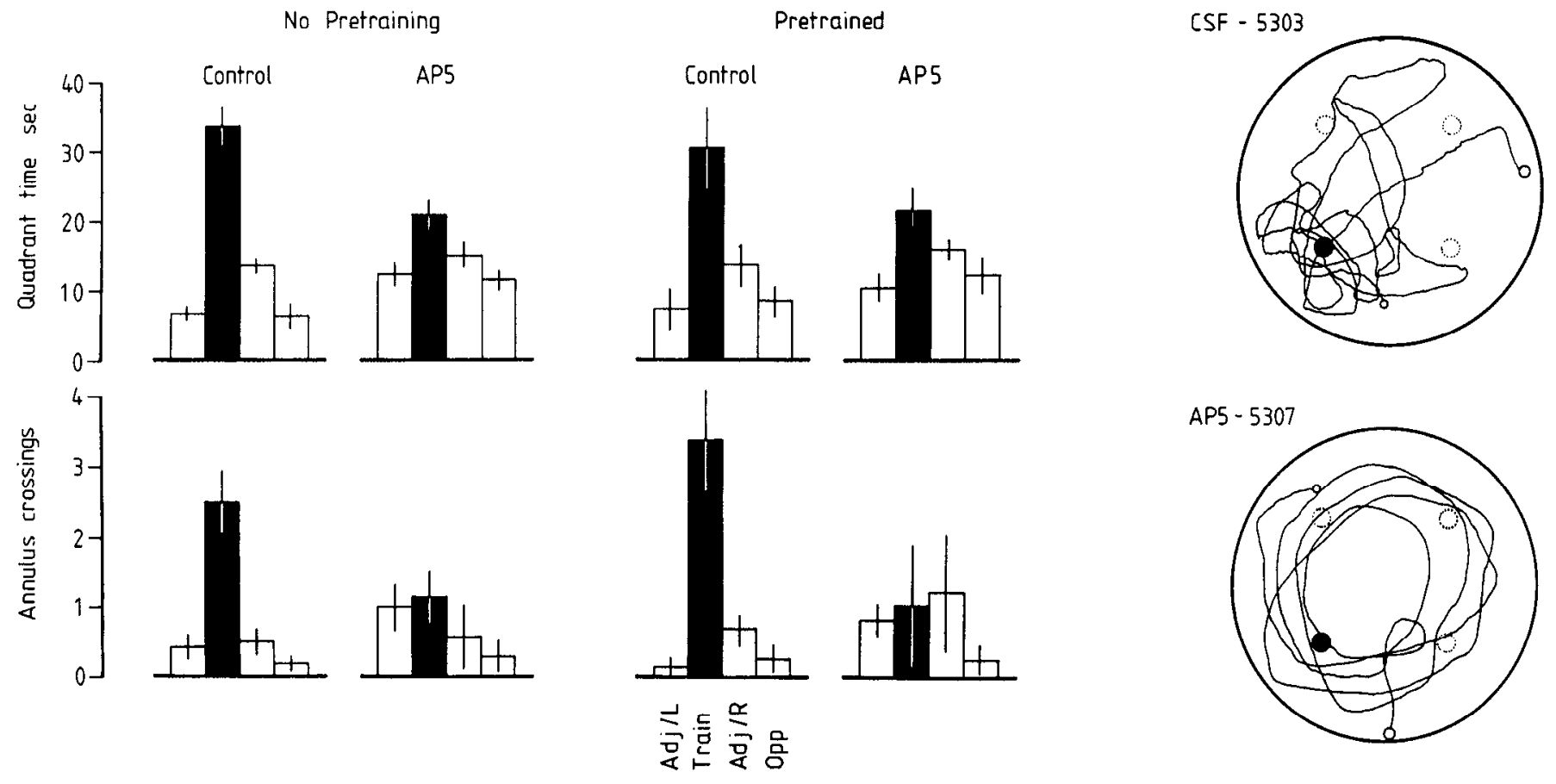

Figure 6. Experiment 3. Top row, Mean times (sec \pm 1 SEM) spent in each of the 4 quadrants of the pool, organized with respect to the training quadrant (NE or SW). Note the differential spatial distribution by control and AP5 groups, but the similarity of pretrained and nonpretrained rats. Bottom row, Mean numbers of crossings of annuli occupying the same surface area as the platform and arbitrarily located at the central position of each quadrant. The highly biased spatial distribution of crossings in control rats reflects the acuity of their memory for the exact former platform location, while the AP5 groups show little spatial bias. Right-hand column, Paths taken during the transfer test by the median rat of each group.

provided an opportunity to measure (a) path lengths and (b) path directionality (heading angles). The overall mean path length for the $60 \mathrm{sec}$ test was $16.1 \mathrm{~m}$, corresponding to a swimming speed of $26.9 \mathrm{~cm} / \mathrm{sec}$. In the analysis of path length, both pretraining $(F=7.1, d f 1 / 30, p<0.025)$ and groups $(F=14.1$, df $1 / 30, p<0.001$ ) were significant, but, as above, these factors did not interact $(F<1)$. The form of the pretraining effect is of interest: the pretrained rats swam an average of $17.2 \mathrm{~m}$ during the transfer test while the posttraining-only rats swam the lesser distance of $15.0 \mathrm{~m}$. I suspect that this difference reflects an unexpected consequence of pretraining, namely a tendency to search for the platform in many different parts of the pool. A faster swimming speed exactly compensates for this tendency, so that the pretrained rats do not, as we have seen, end up spending less time in the correct training quadrant than rats given only posttraining.

Path directionality has been measured in different ways in different laboratories (cf. Whishaw, 1985; Sutherland et al., 1988). The present analysis was conducted on average values of the heading direction measured automatically by the computer at 10 points along each rat's path beginning at $50 \mathrm{~cm}$. The reason for taking so many points is because (a) well-trained rats often stop and look around the room (and at such times may be pointing in the wrong direction) and (b) a rat may be pointing in completely the wrong direction on occasions when it just misses a platform after an otherwise direct path. I have consistently found that analyses based on a smaller sample of values are rarely significant because of high group variance. For each of the 10 values per rat used here, the computer calculated a tangent to the rat's path at the $50 \mathrm{~cm}$ point (point $N$ ) drawing a line between point $N$ and point $N+5$ (i.e., 0.5 sec later; sample rate $=10 \mathrm{~Hz}$ ). It then measured the angle between this tangent and a line drawn from point $N$ to the center of where the platform had been located during training trials. This angle could be between 0 and $+180^{\circ}$ or 0 and $-180^{\circ}$. The computer then did the same for point $N+l$, and so on. These 10 values were averaged using circular statistics to obtain the mean (argument) of the vector expressing the main direction that the animal had been swimming for a period of $1 \mathrm{sec}$. However, rather than use circular statistics for the analysis of variance (which are computationally cumbersome), I analyzed the "modulus" of the arguments (i.e., without regard to sign) using conventional analyses of variance. Effectively, this is a measure of "dispersion" from the correct direction (an analysis taking sign into account would give mean values close to zero for all groups because rats heading to the left would tend to balance out rats heading to the right). At no point in this entire sequence could subjectivity influence the result as all measures were computed automatically from the digitized output of the tracking device. However, although the resulting overall analysis of path-directionality dispersion showed that AP5 rats swam in a less direct way towards the platform than controls (see Table 2), the only significant difference was between the posttrained groups $(F=6.2, d f 1 /$ $19, p<0.025)$. Presumably, pretrained control rats continued to take circuitous routes to the platform because of some residual effect of the earlier pretraining (during which the platform had been in many different places around the pool).

Cerebral distribution of AP5. Table 3 shows the distribution of AP5 in whole tissue across brain regions. Although AP5 concentration showed a tendency to decline as a function of distance from the intraventricular cannula (adjacent to the right hippocampus), the drug was present in each of the measured brain areas in appreciable concentrations. Formal analysis indicated that the concentration in pretraining rats (killed $10 \mathrm{~d}$ 
Table 2. Path directionality (Dispersion from correct angle in degrees \pm 1 SEM)

\begin{tabular}{ll} 
Groups & Angle \\
\hline Posttrained only & \\
Control & $36 \pm 13$ \\
AP5 & $46 \pm 17$ \\
Pretrained & \\
Control & $18 \pm 4$ \\
AP5 & $43 \pm 11$ \\
\hline
\end{tabular}

after surgery) may have been higher than that in posttrainingonly rats (killed after $14 \mathrm{~d}$ ) but that this trend did not reach statistical significance $(F=1.3, d f 1 / 10, p>0.25)$. The trend may reflect changes in uptake or membrane binding of the drug over time. The same analysis also failed to show a significant differential distribution across brain areas $(F=3.0$, df $2 / 20$, $0.10>p>0.05$ ).

\section{Discussion}

Pretraining caused a substantial diminution of the sensorimotor dysfunction, but this had no effect on the drug-induced spatial learning impairment; these 2 effects of drug administration were statistically independent. This experiment therefore provides evidence that AP5 causes a true impairment in learning, with the simplest interpretation being that hippocampal NMDA receptors directly participate in some aspect of processing, storage, or retrieval of information during place navigation. There was no indication that the AP5 rats suffered any lack of motivation to learn the task: they searched for the platform, climbed onto it on contact, and, once on, turned and reared as if attempting to learn its location (Sutherland and Dyck, 1984). Nevertheless, little spatial learning occurred, and the internal consistency of the various measures of spatial performance gives grounds for confidence that the impairment is highly reproducible.

The second main finding was that intraventricular infusion resulted in widespread diffusion of AP5 throughout the forebrain in both the pre- and posttraining groups (which did not differ). The whole tissue concentration tended to be highest in the right hippocampus $(0.56 \mathrm{~nm} / \mathrm{mg}$ wet weight $)$, but this trend did not reach statistical significance. The only other mention of cerebral diffusion of AP5 of which I am aware is in Kleinschmidt et al. (1987), who find an approximately exponential decline over 15 $\mathrm{mm}$ of cat cortical tissue from a peak whole tissue concentration similar to the present findings for hippocampus (M. Bear, personal communication). The difference between these 2 results probably can be accounted for in terms of differing patterns of diffusion with intraventricular vs intracortical infusion. The mean whole tissue concentration of ca. $0.5 \mathrm{nM} / \mathrm{mg}$ wet weight indicates that, at death, the forebrain contained ca. $750 \mathrm{~nm}$ of AP5. The minipumps initially contained ca. $8000 \mathrm{nM}(200 \mu 1$ of $40 \mathrm{~mm}$ AP5), of which about $80 \%$ would have been discharged by the time of death. Thus, the brain contained only $12.5 \%$ of the AP5 that had been infused. The remainder presumably diffused into the spinal cord and blood stream (Davson et al., 1982). However, despite low retention within the forebrain, the whole tissue level does suggest that the extracellular concentration may be as high as $500 \mu \mathrm{M}$, perhaps even higher assuming that (a) extracellular space represents only a fraction of total tissue volume, and (b) most of the AP5 remains in the extracellular fluid. If correct, these estimates would be worrisome because they are at least one order of magnitude higher than is necessary to block LTP in the in vitro hippocampal slice (Harris et al., 1984), and high enough to cause nonspecific effects on kainate/quisqualatemediated synaptic transmission. However, there is no reason to assume that all the AP5 remains in the extracellular fluid. Pilot experiments by S. F. Butcher in Edinburgh and by $\mathbf{M}$. Kessler in Irvine (personal communication) indicate that AP5 is not taken up into cells on the high-affinity glutamate transport system, but this does not rule out the possibility of intracellular transport via other carriers or binding to the external surface of cell membranes (Butcher et al., unpublished observations). Furthermore, preliminary measurements of extracellular concentration using microdialysis indicate that the true functional concentration is much lower than these calculations would imply.

\section{Experiment 4: does AP5 affect the retention of spatial information? \\ Purpose}

In each of 2 experiments revealing a deficit in place navigation, the spatial learning phase has occurred in the presence of AP5. However, AP5 may be having its effects during either learning or retrieval. The simplest way to dissociate these possibilities is to give place navigation training prior to testing the animals in the presence of AP5. An analogous experiment was conducted by McNaughton et al. (1986), who found that well-established spatial performance was unaffected by saturation of hippocampal LTP. In the present case, no drug-induced deficit should occur if AP5 affects only learning, whereas an impairment would reflect an involvement in information retrieval.

\section{Procedure}

Two groups of rats [D,L-AP5, $n=8$; control, $n=7$ (aCSF, $n=$ 5 ; unoperated, $n=2$ )] were trained over 2 main phases separated by surgery as follows.

In phase 1 (days -6 to -2 ), all rats were trained to find a fixed platform for 15 trials over $5 \mathrm{~d}$ according to the usual protocol (except that the ITI was changed to $30 \mathrm{sec}$ for reasons of convenience). The rats were given a transfer test on day -1 and assigned to groups on the basis of their performance. This test was immediately followed by 8 trials (to "reinstate" the

Table 3. Whole tissue amounts of AP5 in several brain areas (nmol/mg wet weight, +1 SEM)

\begin{tabular}{lllllll} 
& \multicolumn{2}{l}{ Brain area } & & & & \\
\cline { 2 - 6 } Group & Visual cortex & Right hippocampus & Left hippocampus & Anterior striatum & Dorsal frontal cortex & Mean \\
\hline Posttrained only & $0.39 \pm 0.07$ & $0.51 \pm 0.06$ & $0.39 \pm 0.10$ & - & - & $0.42 \pm 0.06$ \\
Pretrained & $0.39 \pm 0.04$ & $0.61 \pm 0.13$ & $0.53 \pm 0.15$ & $0.45 \pm 0.06$ & $0.39 \pm 0.06$ & $0.47 \pm 0.05$ \\
\hline
\end{tabular}




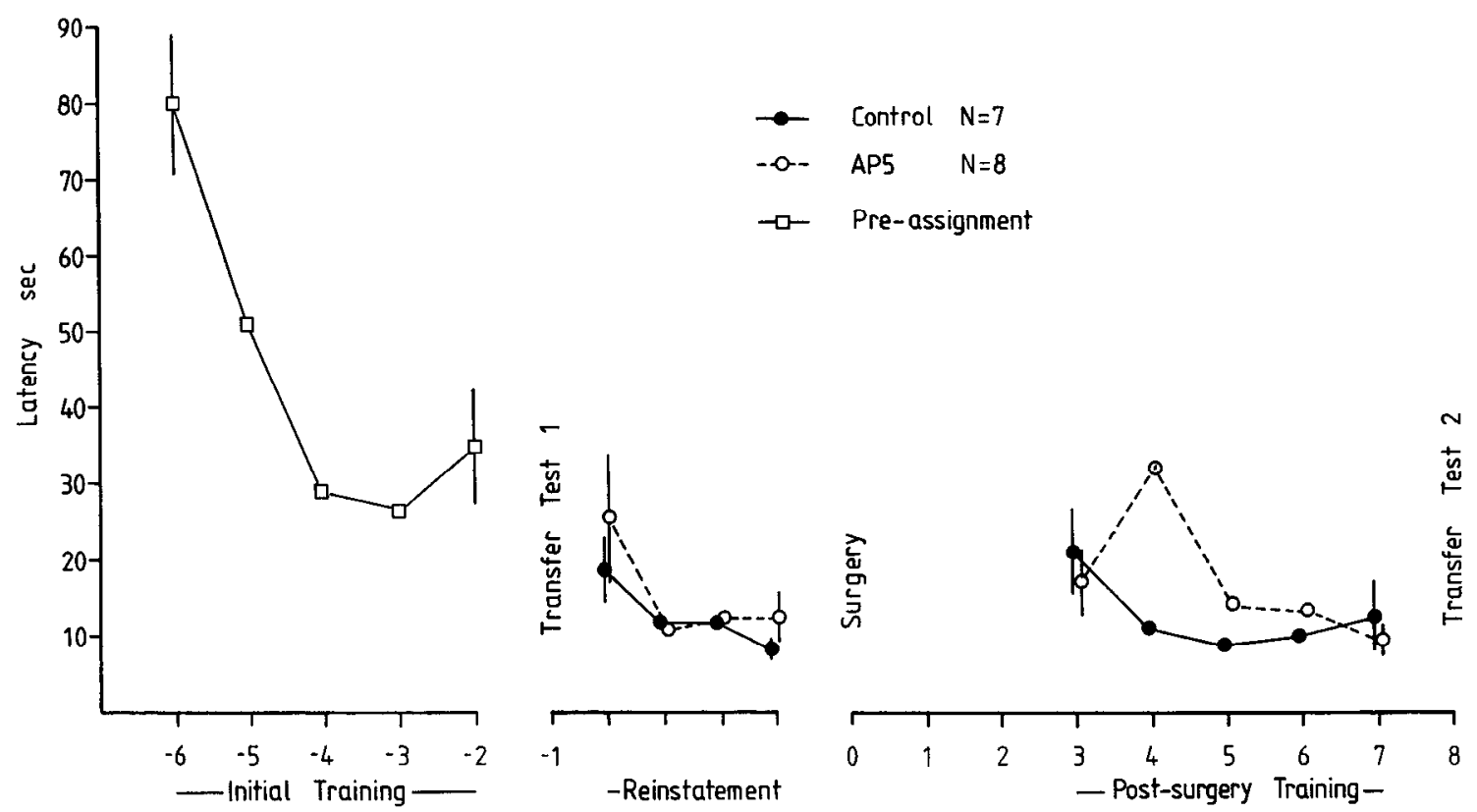

Figure 7. Experiment 4. Mean latency of escape ( $\sec \pm 1$ SEM) for each of the $15 \mathrm{~d}$ of behavioral testing. Phase $1=$ days -6 to -1 ; phase $2=$ days 3 to 8 . The rats were assigned to groups on their performance during the first transfer test but not actually given minipumps until surgery on day 0 . The D,L-AP5 group showed no significant impairment of escape latency during the postsurgery training.

memory of where the platform was located after the transfer test). Surgery was conducted on day 0 .

In phase 2 (days 3 to 8 postsurgery and -implantation of minipumps), all rats were given a further 15 trials ( 3 trials $/ \mathrm{d}$ ) followed, on day 8 , by a second transfer test. Individual rats were trained to find the platform in the same location as it had occupied in phase 1, 2 positions for the platform (NE and SW) being counterbalanced across groups.

Because the author moved during the course of these experiments, this study was conducted in a new laboratory at the University of Edinburgh. The arrangement of the room and tracking system was essentially identical to that used previously at St. Andrews.

\section{Results}

The main finding was that AP5 failed to influence retention (Figs. 7 and 8). The rats, which were later to receive AP5 in minipumps or serve as controls, were deliberately matched during phase 1 . There was therefore no difference between these groups with respect to escape latency or transfer test scores $(F \mathrm{~s}$ $<1)$. In absolute terms, the mean escape latency declined from $104.6 \mathrm{sec}$ to $25.4 \mathrm{sec}$ over the first 15 trials of training and from 27.1 to $8.1 \mathrm{sec}$ during the 8 reinstatement trials.

The crucial data of interest are whether AP5 caused any disruption during phase 2 . The result is clear cut. There was no disruption of escape latency (groups: $F<1$ ) and no difference between groups in their spatial bias during the second transfer test (groups $\times$ quadrants: $F<1$ ). In absolute terms, performance during the second transfer test was better than that during the first (percentage time spent in the training quadrant: phase $1=$ $44 \%$; phase $2=57 \%$; tests $\times$ quadrants: $F=3.91$, df $2 / 39, p$ $<0.025$ ). It might be expected that any improvement in performance between transfer tests would be restricted to the control group. That this did not occur could be due to spatial learning by the AP5 group after surgery, but there is a weakness in the experimental design because it may alternatively reflect learning that occurred during the reinstatement trials immediately prior to surgical implantation of the minipumps. Relevant to this is that analysis of escape latency in phase 2 showed no improvement across days $(F=1.71, d f 4 / 52, p>0.10)$, suggesting that most of the learning about the platform location was indeed complete by the end of phase 1 . However, during phase 2 , both groups did show a slight within-day improvement in escape latency over the 3 trials of each day $(F=3.81$, $d f$ $2 / 26, p<0.05$ ).

\section{Discussion}

The results of this study complement those reported by McNaughton et al. (1986). Rats given sufficient spatial training prior to intraventricular infusion of AP5 continued to perform well when they had to find the escape platform in the same location in space. The simplest interpretation is that AP5 does not affect the retention of spatial information and, by inference, that effects seen in earlier experiments reflect an involvement of NMDA receptors in the processing or storage of information.

A further point is that there is also a suggestion (but little more) that short-term memory is unaffected by AP5. In this experiment, unlike experiments 1 and 3 , the ITI was $30 \mathrm{sec}$. All rats showed a within-day improvement in escape latency during phase 2 that was statistically significant. Over the $5 \mathrm{~d}$ of phase 2 training, the mean escape latency was $19.3 \mathrm{sec}$ on trial 1 and $12.9 \mathrm{sec}$ on trials 2 and 3. Rapid escape on trial 1 requires retrieval from long-term memory, while performance on trials 2 and 3 can be guided by either long-term memory or shortterm/working memory. The data are hardly definitive and suggest the need for more detailed experimentation. However, McNaughton et al. (1986) found that physiological saturation of LTP had no effect on the performance of an explicit workingmemory task (the radial maze). Comparison of these data with the present results is suggestive. 


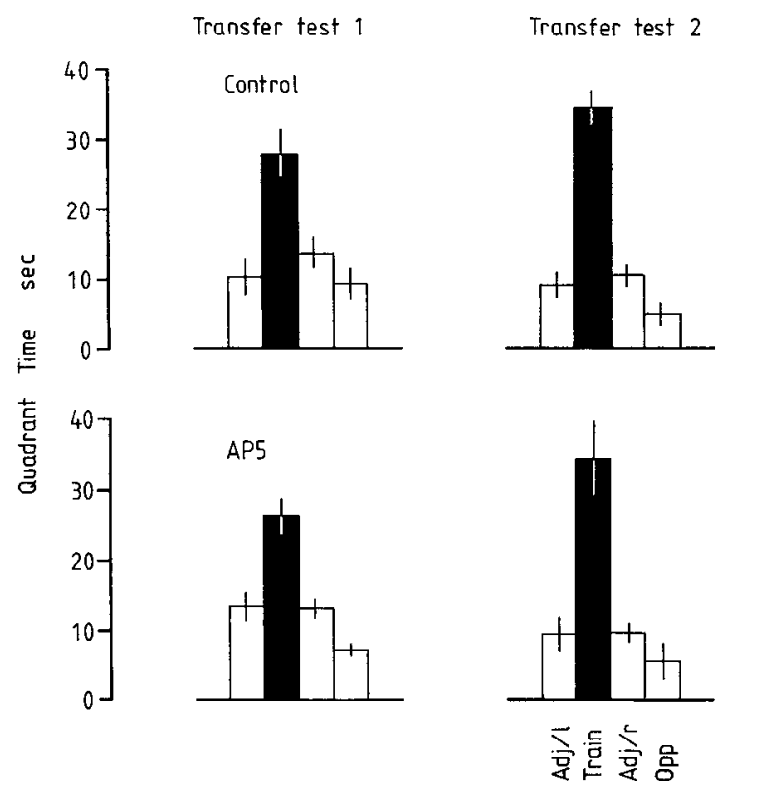

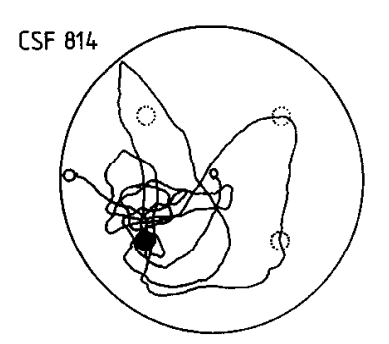

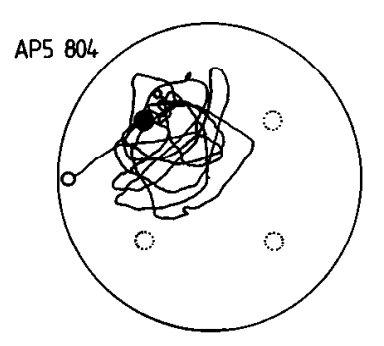

Figure 8. Experiment 4. Mean times (sec \pm 1 SEM) spent in each of the 4 quadrants of the pool by the control (top row) and AP5 (bottom row) groups. The paths taken by the 2 median animals of each group illustrate the spatial bias to the training quadrant in each group.

\section{Experiment 5: does AP5 block hippocampal LTP in vivo? Purpose}

Several studies have shown that AP5 causes a blockade of hippocampal LTP in the in vitro hippocampal slice (Collingridge et al., 1983; Harris et al., 1984; see Collingridge and Bliss, 1987). Whether AP5 causes its impairment of learning by virtue of an effect upon hippocampal LTP will be discussed below, but it was clearly essential to establish whether intraventricular infusion of AP5 over several days would also block hippocampal LTP in vivo. After the present study was conducted, Errington et al. (1987) reported that AP5 blocks LTP in vivo when infused into the molecular layer of the dentate gyrus for $30 \mathrm{~min}$ via a push-pull cannula. There is still value in reporting the present study because it was conducted using essentially the same infusion protocol as that used in the behavioral experiments.

\section{Procedure}

Three groups of rats [D,L-AP5, $40 \mathrm{~mm}, n=9 ; \mathrm{L}-\mathrm{AP} 5,20 \mathrm{mM}$, $n=6$; control, $n=7$ (saline, $n=3$; unoperated, $n=4$ )] were used in a 2-stage experiment as follows.

In phase 1, the animals were prepared with intraventricular cannulae (into the right lateral ventricle) and minipumps (except the 4 unoperated rats). In phase 2 (6-12 d after minipump implantation), all rats were subject to an acute electrophysiological experiment. The general procedures for both phases have been described in Materials and Methods.

The ventral locations of both the stimulating and recording electrodes were adjusted to maximize the dentate hilus potentials recorded in the main part of the experiment. After stable potentials had been recorded for at least $30 \mathrm{~min}$, a low-frequency $(0.05 \mathrm{~Hz}, 7 \mathrm{~V})$ test series was begun, continuing for $100 \mathrm{~min}$. Two brief bursts of high-frequency activation ( 99 impulses, 100 $\mu \mathrm{sec}$ duration, $400 \mathrm{~Hz}, 7 \mathrm{~V}$ ) were applied exactly 20 and $40 \mathrm{~min}$ into the experiment. In some animals of each group, an input/ output $(\mathrm{I} / \mathrm{O})$ function was constructed using a series of 40 lowfrequency test pulses ( 4 pulses at each of 10 voltage levels from 0 to $9 \mathrm{~V}, 100 \mu \mathrm{sec}, 0.05 \mathrm{~Hz}$ ). The I/O curve was constructed immediately before and immediately after the main test series.
Throughout both the I/O measurements and the test series, measures were taken of (1) the maximum height of the evoked field potential, and (2) the slope of its early rising phase (typically $1.8-2.5$ msec poststimulus), the latter calculated using linear regression. The waveform was sampled at $10 \mathrm{kHz}$ using a Minc 11/23 computer.

\section{Histological analysis}

At the end of the experiment, the brains of several of the animals were subject to routine histological analysis to identify the locations of the stimulating and recording electrodes. The results showed that the recording electrode tip was always just below the inner blade of the granule cells in the dentate gyrus, and the stimulating electrode within or adjacent to the angular bundle (data not shown).

\section{Results}

The main finding was that the 6-12-d intraventricular infusion of D,L-AP5 caused a total blockade of the induction of LTP in vivo while having no detectable effect on the slope or maximal amplitude of the baseline evoked field potentials. L-AP5 also had no effect on baseline field potentials. However, although not blocking LTP, it did appear to cause a faster decay of synaptic enhancement over the course of the 100 min test series. The main findings are presented in Figure 9 and Table 4.

The maximal amounts of LTP and the associated decay time constant were calculated by solving the standard equation:

$$
Y=A \cdot \mathrm{e}^{-1 / \tau \cdot t}
$$

where $Y$ is the percentage increase in slope at time $t, A$ is the maximal LTP (abscissa at time $t=0$ ), and $\tau$ is the decay time constant. These parameters were calculated using the group mean data of the slope function between the 50th and the 100th minute of the test series, as shown in Figure 9. The calculations were conducted by linear regression of (1) the natural logarithm of the percentage increase in slope above baseline, against (2) the absolute time ( $\mathrm{min}$ ) measured from the delivery of the second burst of high-frequency activation. Therefore no estimate of the variability in $\tau$ was calculated, although infusion of L-AP5 ap- 


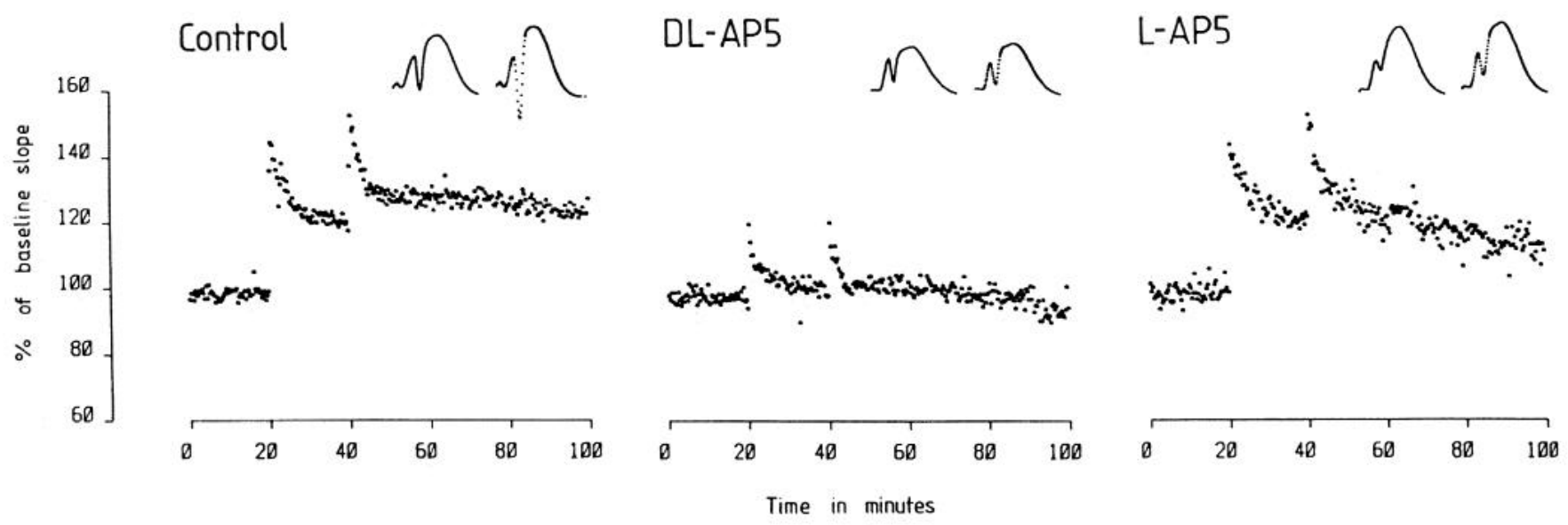

Figure 9. Experiment 5. Mean normalized slope values for the $100 \mathrm{~min}$ test series. Low-frequency stimulation was given throughout, except for 2 brief bursts of high-frequency stimulation at 20 and $40 \mathrm{~min}$ into the test series. Note blockade of LTP by D,L-AP5 and the apparently faster decay in the L-AP5 group.

peared to cause a more rapid decay of LTP over the course of the test series. This picture is confirmed in the $\mathrm{I} / \mathrm{O}$ curves based on a sample of the animals in each group (Fig. 10).

In the I/O functions, the control group $(n=7)$ showed a significant increase in the slope function across a range of stimulus intensities $(F=27.5, d f 1 / 6, p<0.005)$, while the D,L-AP5 group $(n=5)$ showed no effect of high-frequency stimulation $(F<1)$. The $11 \%$ increase in slope present at the end of the test series in the L-AP5 group $(n=5)$ did not quite reach significance $(F=4.0, d f 1 / 4, p>0.10)$. There seemed little point in increasing the number of animals in the L-AP5 group, as the decay time constant of $65 \mathrm{~min}$ was such as to make it inevitable that some L-AP5 rats would show little LTP at the end of the test series while others would show a residual effect. Moreover, the results of Racine et al. (1983) indicate that acute experiments are poor tests of the time course of LTP.

\section{Discussion}

Intraventricular infusion of D,L-AP5 by the same route and at the same concentration as that used in the behavioral experiments caused a total blockade of LTP in vivo. While this result does not prove that the behavioral effects of AP5 are mediated via its effect on hippocampal synaptic plasticity, it certainly gives no grounds for rejecting such a hypothesis.

\section{General Discussion}

The hypothesis that the physical substrate of memory in the mammalian brain resides in alterations of synaptic efficacy has been proposed frequently (Hebb, 1949; Marr, 1971; Goddard, 1980; Eccles, 1983; McNaughton, 1983; Lynch and Baudry,
1984; McNaughton and Morris, 1987) and is widely accepted by many neuroscientists. However, as learning and memory are fundamentally psychological concepts inferred from alterations in behavior in response to experience, valid tests of any specific version of this hypothesis necessitate a combination of physiological and behavioral experimentation. The present results confirm and extend other work pointing to a link between one particular form of synaptic plasticity and learning. The major finding was that intracerebral infusion of the NMDA receptor antagonists AP5, at a concentration sufficient to cause a total blockade of hippocampal LTP without effect on normal fast synaptic transmission, caused a behaviorally selective impairment in learning. Spatial learning was impaired; visual discrimination learning was not. The retention of well-established spatial information also was unaffected. These results suggest that the type of synaptic plasticity studied in LTP experiments (1) is involved in some but not in all kinds of learning, and (2) is involved in the initial associative phase of learning but not in retrieval. This conclusion is subject to the qualification that no unequivocal demonstration that alterations of synaptic efficacy play a causal role in the storage of information in the mammalian brain has yet, to my knowledge, been reported; the present results represent no exception to this claim.

These findings extend those of McNaughton et al. (1986), who showed that high-frequency activation of the perforant path sufficient to induce long-term enhancement of synaptic efficacy in the dentate gyrus caused an anterograde impairment in the learning of Barnes' (1979) circular platform task. Taken together, these studies indicate that 2 radically different treatments (AP5 administration and high-frequency stimulation) whose only

Table 4. Absolute values of slope and amplitude of dentate hilus evoked field potentials in Expt 4

\begin{tabular}{llllllrr} 
Group & Slope & Amplitude & $\begin{array}{l}\text { MTP \% } \\
\text { LTPal }\end{array}$ & \multicolumn{3}{c}{ T (min) } & \multicolumn{3}{c}{ LTP \% at times (min) } \\
\hline Control & $1.95 \pm 0.37$ & $6.21 \pm 1.28$ & 30.4 & 250 & 27.9 & 25.4 & 23.3 \\
D,L-AP5 & $2.39 \pm 0.57$ & $6.59 \pm 1.38$ & - & - & -0.1 & -1.6 & -6.3 \\
L-AP5 & $2.45 \pm 0.55$ & $7.65 \pm 1.73$ & 30.5 & 67 & 22.4 & 18.0 & 11.7 \\
\hline
\end{tabular}

Parameters of LTP calculated from the regression analysis. 

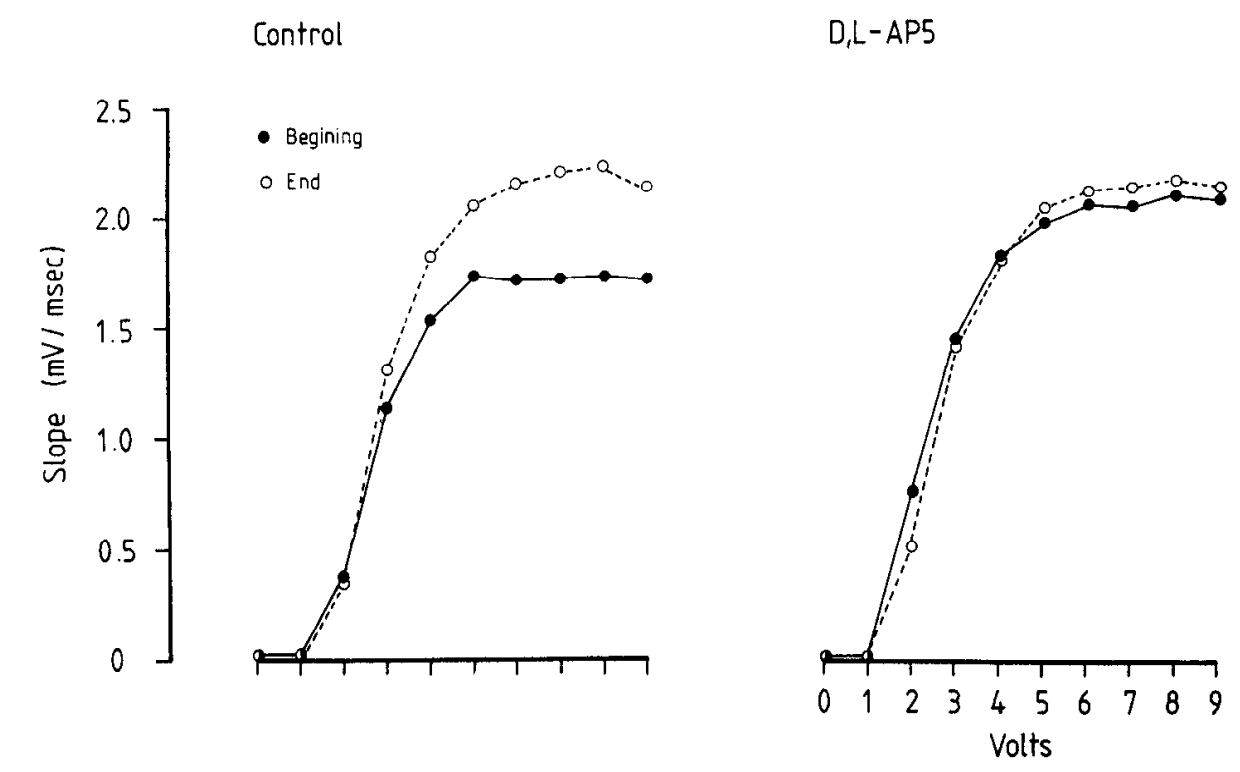

L-AP5

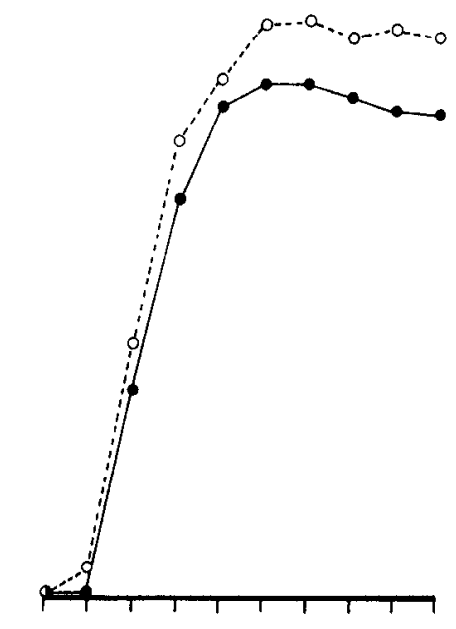

Figure 10. Experiment 5. I/O curves for those animals of each group for whom observations were taken at the beginning and end of the test series.

obvious common feature is their consequence of blocking synaptic plasticity have the equivalent behavioral effect of causing an impairment of one type of representational learning. In contrast to Berger's (1984) experiment showing that saturating hippocampal LTP improves subsequent nictitating membrane conditioning and both Reymann et al.'s (1982) and Skelton et al.'s (1985) intriguing observations concerning the use of perforant path stimulation as a conditioned stimulus, it seems not to matter for spatial learning whether synaptic efficacy is blocked at its nominal baseline (by a drug) or at its asymptote (by a physiological treatment).

There may, however, be subtle differences in the effects of these 2 treatments. First, their side effects are different. AP5 can cause sensorimotor side effects such as mild ataxia, a disruption of suprasegmental reflexes, muscle relaxation, and, perhaps, somatosensory neglect. Physiological induction of LTP to asymptote by high-frequency electrical stimulation can cause seizures. Just as McNaughton et al. (1986) were careful to exclude the possibility that seizures contributed to the anterograde spatial amnesia, so in the present study effort has been expended to dissociate the learning impairment from other drug-induced behavioral effects. It is worth emphasizing that these side effects were relatively mild and certainly nowhere near as severe as those seen after intraperitoneal injections of noncompetitive NMDA antagonists such as phencyclidine (Snell and Johnson, 1988) or MK-801 (Wong et al., 1986; Kemp et al., 1987). These compounds induce a severe head movement stereotopy at doses that give rise to the use-dependent blockade of NMDA receptors characteristic of noncompetitive antagonists. Competitive NMDA antagonists appear to cause similar effects only at very high doses (Koek et al., 1987; Snell and Johnson, 1988). The results of experiment 3 of the present series indicate that these side effects are statistically independent of the effects of AP5 on spatial learning.

A second difference between LTP induction and AP5 infusion is that they should have different effects if given immediately after training trials. Saturating LTP immediately after new learn- ing but before long-term memories are stored in cortex (Sutherland et al., 1988) should, and does, cause a disruption of spatial information temporarily stored in hippocampus via synaptic plasticity (McNaughton et al., 1986; experiment 2). Posttrial infusions of AP5, on the other hand, would not be expected to impair recently acquired information as the drug would not alter the recently changed synaptic weights. This prediction has not yet been tested. However, a general implication of this point is that the relative merits of pretrial vs posttrial infusion of drugs for investigating the pharmacology of memory must be assessed in relation to their detailed neuropharmacological mechanisms of action.

The discussion so far implicitly assumes that AP5 causes its effects on learning by blocking hippocampal synaptic plasticity. As noted above, this conclusion is not demanded by the present experiments. The logical difficulty is as follows: blockade of LTP by AP5 is a dependent consequence of the drug treatment. The impairment of lcarning is also a dependent consequence. However, it is fallacious to presume that one dependent consequence is necessarily the cause of the other. Further work is required to resolve this crucial point. Indeed, AP5 may be having a direct effect on learning via some other mechanism. Leung and Desborough's (1988) recent demonstration that high doses of intraventricular AP5 block atropine-sensitive hippocampal slowwave activity ("theta") indicates that this is more than an academic possibility.

Nevertheless, it is clear that LTP has several properties that render it an attractive candidate as a substrate for information storage: (1) in chronic recording preparations, it can be very long lasting (Barnes, 1979) and its decay time course correlates with the rate of forgetting of spatial information (Barnes and McNaughton, 1985); (2) it can be induced rapidly, in less than $1 \mathrm{~min}$ (McNaughton, 1983), as might be expected for the initial formation of a physical memory tracc; (3) its induction requires the conjunction of presynaptic activity and postsynaptic depolarization (McNaughton et al., 1978; Kelso et al., 1986; Wigstrom et al., 1986; see Brown et al., 1988), suggestive of a Hebb- 
like synaptic learning rule in which the postsynaptic neuron controls association formation (see below); (4) the synaptic change is homosynaptic to the sites of afferent stimulation (at least in area CA1: Anderson et al., 1977; Lynch et al., 1977; Barrinuevo and Brown, 1983) providing for massive storage capacity; (5) LTP occurs in brain structures believed to play a role in learning, such as the hippocampus and neocortex (Bliss and Lomo, 1973; Lee, 1983; Racine et al., 1983; Artola and Singer, 1987); and (6) the local circuitry of these brain regions is commensurate with physiologically realistic "distributed-storage" networks functioning as "content-addressable" associative memory systems (Willshaw et al., 1969; Marr, 1971; Hinton and Anderson, 1981; Lynch, 1986; McNaughton and Morris, 1987) or as "competitive-learning" networks (Grossberg, 1982; Rolls, 1987).

Indeed, the possibility that NMDA receptors participate in certain types of learning is intriguing, as it suggests a mechanism by which certain logical requirements of a distributed memory system of the kind envisaged by Marr (1971) can be met. NMDApreferring receptors endow neurons with the biophysical capacity to detect the conjunction of 2 events. They do this by virtue of having an unusual current-voltage relationship such that they become active only on depolarization. Studies on neurons from neonatal rat brain (Nowak et al., 1984), mouse spinal neurons in culture (Mayer et al., 1984), and rat cortical slices (Thomson et al., 1985) have each shown that at physiological concentrations of $\mathrm{Mg}^{2+}$, inward current to iontophoretically applied NMDA is minimal when the target cell is at the resting potential, but that it rises on partial depolarization. This curious property of the NMDA receptor is an attractive and suitable neuron mechanism for initiating the process of association formation. There are at least 2 ways in which the mechanism might work: one way is that sequential activation of a cell by 2 inputs ( $A$ and $B$ ) would allow the second $B$ input to activate NMDA-receptorassociated ion channels following partial depolarization of the cell by input $A$; the second way would involve modulating the level of excitability of a dendrite (or part of a dendrite) by other depolarizing inputs so that any input (A, B, etc.) to a synapse containing NMDA receptors could then open the NMDA-associated ion channels. In either case, activation of NMDA receptors is merely the first step of a cascade of intracellular processes involving (a) a massive influx of calcium (Murphy et al., 1987) and (b) activation of second-messenger systems that eventually result in altered expression of synaptic efficacy [e.g., calpain (Lynch and Baudry, 1984); arachidonic acid (Bliss and Lynch, 1988); protein F1 (Routtenberg et al., 1985)]. The alteration of synaptic efficacy could then be expressed as (a) an increase in presynaptic transmitter release (Errington et al., 1987; see Bliss and Lynch, 1988), (b) a change in postsynaptic receptor number or conformation (Lynch and Baudry, 1984; McCabe and Horn, 1988), or (c) a change in the ion-channel conductance substates activated by the endogenous transmitter binding to kainate/quisqualate receptors (see Mayer and Westbrook, 1987).

Thus, NMDA receptors endow neurons with a biophysical property necessary for them to function as association devices, operating on their input according to a quasi-Hebbian learning principle. Rather than requiring a conjunction of afferent stimulation and postsynaptic discharge, activation of NMDA receptors requires a conjunction of afferent activity and postsynaptic depolarization. Furthermore, because the hippocampal circuitry within which they are embedded involves a matrix arrangement with numerous synapses en passage and feedforward inhibition for thresholding, the neurons of the dentate gyrus and area CA1 could be functioning as a distributed memory system of the kind envisaged by Willshaw et al. (1969). McNaughton and Morris (1987) have recently elaborated this proposal qualitatively, but quantitative system-level models need to be constructed. In making biologically realistic models of hippocampal function, area CA3 will be of particular interest because the precise lamella-specific projection from the dentate gyrus terminates at mossy fiber boutons that show a nonassociative AP5-insensitive LTP (Harris and Cotman, 1986; Nicoll et al., 1988). A further important issue will be whether downregulation of synaptic efficacy within the hippocampus is under associative control or is a strictly time-dependent process.

The reason why antagonism of NMDA receptors causes a selective disruption of spatial learning is unclear. An important factor must be that NMDA receptors have their highest density in hippocampus (Monaghan and Cotman, 1985). This structure responds to spatial features of the environment (O'Keefe, 1976) and "place cells" fire in a bursting mode that could be symptomatic of current flow through the ion channels associated with NMDA receptors. The spatial learning task used in these experiments is relatively resistant to lesions of structures other than the hippocampus, including amygdala and parietal lesions (Kolb et al., 1983; Sutherland et al., 1983), and only a transitory impairment (if any) is seen after lesions of the nucleus basalis magnocellularis (Whishaw et al., 1985; Hagan et al., 1988). However, the hippocampus is clearly not the only structure involved in spatial learning-Sutherland et al. (1988) have recently shown that lesions of the posterior retrosplenial cortex also cause a severe impairment-nor is spatial learning the only type of learning with which the hippocampus is involved (Squire, 1987). It is important to recognizc, morcover, that the cffects of NMDA antagonists, leaving normal synaptic transmission intact, are liable to be unlike a lesion in detail. Indeed, the question arises as to what cognitive functions normally damaged by hippocampal and neocortical lesions are spared by a drug with AP5's profile of action. More detailed study of the behavioral effects of AP5 and of other NMDA antagonists is presently underway (Morris et al., 1989). An important issue is whether other forms of representational memory are also affected (Tonkiss et al., 1988).

A possible clinical implication of the present findings arises in the context of the search for new anticonvulsants. AP5 and the closely related compound AP7 both prevent the induction of sound-induced seizures (Croucher et al., 1982). Other NMDA antagonists with better penetration of the blood-brain barrier (e.g., MK-801) have been subject to investigation in clinical trials. However, one factor to consider in the design of new anticonvulsants is the reduction of cognitive side effects, because these can be caused by anticonvulsant drugs in current clinical use (e.g., phenytoin and valproate: Thompson and Trimble, 1982; Reynolds, 1983). Although such problems may not be as important with regard to the development of drugs for preventing brain damage after ischemia, the present results indicate the desirability, if nothing else, of including appropriate neuropsychological testing in the development and clinical trials of new compounds designed with a view to controlling excitatory neurotransmission (Meldrum, 1985).

\section{References}

Andersen, P., S. H. Sundberg, O. Sveen, and H. Wigstrom (1977) Specific long-lasting potentiation of synaptic transmission in hippocampal slices. Nature 266: 736-737. 
Artola, A., and W. Singer (1987) Long-term potentiation and NMDA receptors in rat visual cortex. Nature 330: 649-652.

Barnes, C. A. (1979) Memory deficits associated with senescence: A neurophysiological and behavioural study in the rat. J. Comp. Physiol. Psychol. 93: 74-104.

Barnes, C. A., and B. L. McNaughton (1985) An age comparison of the rates of acquisition and forgetting of spatial information in relation to long-term enhancement of hippocampal synapses. Behav. Neurosci. 99: 1040-1048.

Barrinuevo, G., and T. H. Brown (1983) Associative long-term potentiation in hippocampal slices. Proc. Natl. Acad. Sci. USA 80:73477351.

Bass, N., and P. Lundborg (1973) Postnatal development of bulk flow in the cerebrospinal fluid system of the albino rat: Clearance of carboxyl-[14C]-inulin after intrathecal infusion. Brain Res. 52: 323-332.

Bear, M. F., L. N. Cooper, and F. F. Ebner (1987) A physiological basis for a theory of synapse modification. Science $237: 42-48$.

Berger, T. W. (1984) Long-term potentiation of hippocampal synaptic transmission affects rate of behavioural learning. Science 224: 627630.

Bliss, T. V. P., and T. Lomo (1973) Long-lasting potentiation of synaptic transmission in the dentate area of the anaesthetised rabbit following stimulation of the perforant path. J. Physiol. (Lond.) 232: 331-356.

Bliss, T. V. P., and M. A. Lynch (1988) Long-term potentiation of synaptic transmission in the hippocampus: Properties and mechanisms. In Long-Term Potentiation: From Biophysics to Behavior, P. W. Landfield and S. A. Deadwyler, eds., pp. 3-72, Liss, New York.

Brown, T. H., V. C. Chang, A. H. Ganong, C. L. Keenan, and S. R. Kelso (1988) Biophysical properties of dendrites and spines that may control the induction and expression of long-term potentiation. In Long-Term Potentiation: From Biophysics to Behavior, P. W. Landfield and S. A. Deadwyler, eds., pp. 201-264, Liss, New York.

Cahusac, P. M. B., R. H. Evans, R. G. Hill, R. E. Rodriquez, and D. A. S. Smith (1984) The behavioural effects of an N-methylaspartate receptor antagonist following application to the lumbar spinal cord of conscious rats. Neuropharmacology 23: 719-724.

Collingridge, G. L., and T. V. P. Bliss (1987) NMDA rcceptors-their role in long-term potentiation. Trends Neurosci. 10:288-293.

Collingridge, G. L., S. J. Kehl, and H. McLennan (1983) Excitatory amino acids in synaptic transmission in the Schaffer collateral-commissural pathway of the rat hippocampus. J. Physiol. (Lond.) 334: 33-46.

Cotman, C. W., and L. L. Iversen (1987) Excitatory amino acids in the brain-focus on NMDA receptors. Trends Neurosci. 10: 263265.

Croucher, M. J., J. F. Collins, and B. S. Meldrum (1982) Anticonvulsant action of excitatory amino-acid antagonists. Science 216:899901.

Crunelli, V., S. Forda, and J. S. Kelly (1983) Blockade of amino acidinduced depolarizations and inhibition of excitatory post-synaptic potentials in rat dentate gyrus. J. Physiol. (Lond.) 341:627-640.

Davies, J., and J. C. Watkins (1983) Role of excitatory amino acid receptors in mono- and polysynaptic excitation in the spinal cord. Exp. Brain Res. 49: 280-290.

Davson, H., J. G. Hollingsworth, M. B. Carey, and J. D. Fenstermacher (1982) Ventriculo-cisternal perfusion of twelve amino acids in the rabbit. J. Neurobiol. 13: 293-318.

Dingledine, R. (1983) N-methyl aspartate activates voltage-dependent calcium conductance in rat hippocampal pyramidal cells. J. Physiol. (Lond.) 343: 385-405.

Dingledine, R. (1986) NMDA receptors: What do they do? Trends Neurosci. 9: 47-49.

Eccles, J. C. (1983) Calcium in long-term potentiation as a model for memory. Neuroscience 10:1071-1081.

Errington, M. L., M. A. Lynch, and T. V. P. Bliss (1987) Long-tcrm potentiation in the dentate gyrus: Induction and increased glutamate release are blocked by $\mathrm{D}$ (-)amino phosphonvalerate. Neuroscience 20: 279-284.

Foster, A. C., and G. E. Fagg (1984) Acidic amino-acid binding sites in mammalian neuronal membranes: Their characteristics and relationship to synaptic receptors. Brain Res. Rev. 7: 103-164.

Goddard, G. V. (1980) Component properties of the memory machine: Hebb revisited. In The Nature of Thought: Essays in Honor of D. O. Hebb, P. W. Jusczyck and R. M. Klein, eds., pp. 231-247, Erlbaum, Hillsdale, NJ.
Goddard, G. V. (1986) A step nearer a neural substrate. Nature 319: $721-722$.

Grossberg, S. (1982) Studies of Mind and Brain, Reidel, New York.

Hablitz, J. I., and I. A. Langmoen (1986) N-methyl-D-aspartate receptor antagonists reduce synaptic excitation in the hippocampus. J. Neurosci. 6: 102-106.

Hagan, J. J., J. D. Salamone, J. Simpson, S. D. Iversen, and R. G. M. Morris (1988) Place-navigation in rats is impaired by lesions of medial septum and diagonal band but not nucleus basalis magnocellularis. Behav. Brain Res. 27: 9-20.

Harris, E. W., and C. W. Cotman (1986) Long-term potentiation of guinea-pig mossy fiber responses is not blocked by NMDA antagonists. Neurosci. Lett. 70: 132-137.

Harris, E. W., A. H. Ganong, and C. W. Cotman (1984) Long-term potentiation in the hippocampus involves activation of $\mathrm{N}$-methyl-Daspartate receptors. Brain Res. 323: 132-137.

Hebb, D. O. (1949) The Organization of Behavior, Wiley, New York.

Herron, C. E., R. A. Lester, E. I. Coan, and G. L. Collingridge (1986) Frequency-dependent involvement of NMDA receptors in the hippocampus: A novel synaptic mechanism. Nature $322: 265-268$.

Hinton, G., and J. A. Anderson (1981) Parallel Models of Associative Memory, Erlbaum, Hillsdale, NJ.

Jarrard, L. E. (1986) Selective hippocampal lesions and behavior: Implications for current research and theorizing. In The Hippocampus, Vol. 3, R. L. Isaacson and K. H. Pribram, eds., pp. 93-126, Plenum, New York.

Kelso, S. R., A. H. Ganong, and T. H. Brown (1986) Hebbian synapses in hippocampus. Proc. Nat. Acad. Sci. USA 83: 5326-5330.

Kemp, J. A., T. Priestley, R. Gill, and A. C. Foster (1987) MK-801 is a potent and selective N-Methyl-D-aspartate (NMDA) antagonist which following peripheral administration, prevents NMDA-induced neuronal degeneration. In Pharmacology of Cerehral Ischaemia, J. Krieglstein, ed., pp. 397-401, Elsevier, Holland.

Kleinschmidt, A., M. F. Bear, and W. Singer (1987) Blockade of NMDA receptors disrupts experience-dependent plasticity of kitten striate cortex. Science 238: 355-358.

Klockgether, T., M. Schwarz, L. Turski, and K.-H. Sontag (1986) The rat ventromedial thalamic nucleus and motor-control: Role of N-Methyl-D-Aspartate mediated excitation, GABAergic inhibition and muscarinic transmission. J. Neurosci. 6: 1702-1711.

Koek, W., J. H. Woods, and P. Ornstein (1987) A simple and rapid method for assessing similarities among directly observable behavioural effects of drugs: PCP-like effects of 2-amino-5-phosphonovaterate in rats. Psychopharmacology 91: 297-304.

Kolb, B., R. J. Sutherland, and I. Q. Whishaw (1983) A comparison of the contributions of the frontal and parietal association cortex to spatial localisation in rats. Behav. Neurosci. 97: 13-27.

Laroche, S., and V. Bloch (1982) Conditioning of hippocampal cells and long-term potentiation: An approach to mechanisms of posttrial memory facilitation. In Neuronal Plasticity and Memory Formation. C. Ajmone-Marsen and H. Matthies, eds., pp. 575-587, Raven, New York.

Lee, K. (1983) Sustained modification of neuronal activity in the hippocampus and neocortex. In Neurobiology of the Hippocampus, W. Siefert, ed., pp. 265-274, Academic, London.

Leung, L.-W. S., and K. A. Desborough (1988) APV, an N-MethylD-Aspartate receptor antagonist, blocks the hippocampal theta rhythm in behaving rats. Brain Res. 463: 148-152.

Lynch, G. S. (1986) Synapses, Circuits and the Beginnings of Memory, MIT Press, Cambridge, MA.

Lynch, G. S., and M. Baudry (1984) The biochemistry of memory: A new and specific hypothesis. Science 224: 1057-1063.

Lynch, G. S., T. Dunwiddie, and V. Gribkoff (1977) Heterosynaptic depression: A postsynaptic correlate of long-term potentiation. Nature 266: 737-739.

Marr, D. (1971) Simple memory: A theory of archicortex. Philos. Trans. R. Soc. Ser. B. 262: 23-80.

Mayer, M. C., and G. L. Westbrook (1987) The physiology of excitatory amino acids in the vertebrate central nervous system. Prog. Neurobiol. 28: 197-276.

Mayer, M. C., G. L. Westbrook, and P. B. Guthrie (1984) Voltagedependent block by $\mathrm{Mg}^{2+}$ of NMDA response in spinal cord neurones. Nature 309: 261-263.

McCabe, B. J., and G. Horn (1988) Learning and memory: Regional changes in N-methyl-D-aspartate receptors in chick brain after imprinting. Proc. Natl. Acad. Sci. USA 85: 2849-2853. 
McLennan, H. (1984) Receptors for the excitatory amino acids in the mammalian central nervous system. Prog. Neurobiol. 20: 251-271.

McNaughton, B. L. (1983) Activity dependent modulation of hippocampal synaptic efficacy: Some implications for memory process. In Neurobiology of the Hippocampus, W. Siefert, ed., pp. 233-252, Academic, New York.

McNaughton, B. L., and R. G. M. Morris (1987) Hippocampal synaptic enhancement and information storage within a distributed memory system. TINS 10: 408-415.

McNaughton, B. L., R. M. Douglas, and G. V. Goddard (1978) Synaptic enhancement in fascia dentata: Cooperativity among coactive elements. Brain Res. 157: 277-293.

McNaughton, B. L., C. A. Barnes, G. Rao, J. Baldwin, and M. Rasmussen (1986) Long-term enhancement of hippocampal synaptic transmission and the acquisition of spatial information. J. Neurosci. 6: 563-571.

Meldrum, B. S. (1985) Possible therapeutic applications of antagonists of excitatory amino acid neurotransmitters. Clin. Sci. 68: 113-122.

Mishkin, M. (1982) A memory system in the monkey. Philos. Trans. R. Soc. London (Biol.) 298: 85-95.

Mishkin, M., and H. L. Petri (1984) Memories and habits: Some implications for the analysis of learning and retention. In Neuropsychology of Memory, L. R. Squire and N. Butters, eds., pp. 87-296, Guilford, New York.

Monaghan, D. T., and C. W. Cotman (1985) Distribution of N-methylD-aspartate sensitive $\mathrm{I}-\left[{ }^{3} \mathrm{H}\right]$-glutamate binding sites in rat brain. $\mathrm{J}$. Neurosci. 5: 2909-2919.

Morris, R. G. M. (1981) Spatial localisation does not depend on the presence of local cues. Learning and Motivation 12: 239-260.

Morris, R. G. M. (1984) Developments of a water-maze procedure for studying spatial learning in the rat. J. Neurosci. Meth. 11:47-60.

Morris, R. G. M., P. Garrud, J. N. P. Rawlins, and J. O'Keefe (1982) Place navigation impaired in rats with hippocampal lesions. Nature 297: 681-683.

Morris, R. G. M., E. Anderson, G. S. Lynch, and M. Baudry (1986a) Selective impairment of learning and blockade of long-term potentiation by an N-methyl-D-aspartate receptor antagonists, AP 5 . Nature 319: 774-776.

Morris, R. G. M., J. J. Hagan, and J. N. P. Rawlins (1986b) Allocentric spatial learning by hippocampectomised rats: A further test of the "spatial mapping" and "working memory" theories of hippocampal function. Q. J. Exp. Psychol. 38B: 365-395.

Morris, R. G. M., R. F. Halliwell, and N. Bowery (1989) Synaptic plasticity and learning II: Do different kinds of plasticity underlie different kinds of learning? Neuropsychologia 27: 41-59.

Murphy, S. N., S. A. Thayer, and R. J. Miller (1987) The effects of excitatory amino acids on intracellular calcium in single mouse neurons in vitro. J. Neurosci 7: 4145-4158.

Nicoll, R. A., J. A. Kauer, and R. C. Malenka (1988) The current excitement in Long-Term Potentiation. Neuron 1:97-103.

Nowak, L., P. Bregestovski, P. Ascher, A. Herbet, and A. Prochiantz (1984) Magnesium gates glutamate-activated channels in mouse central neurones. Nature 307: 462-465.

O'Keefe, J. (1976) Place-units in the hippocampus of the freely moving rat. Experimental Neurol. 51: 78-109.

O'Keefe, J., and L. Nadel (1978) The Hippocampus as a Cognitive Map, Oxford U.P., Oxford.

Olton, D. S., J. T. Becker, and G. E. Handelmann (1979) Hippocampus, space and memory. Behav. Brain Sci. 2: 313-365.

Olverman, H. J., A. W. Jones, and J. C. Watkins (1984) L-Glutamate has higher affinity than other amino acids for [3H]-D-AP5 binding sites in rat brain membranes. Nature 307: 460-462.

Patel, S., A. G. Chapman, M. H. Millan, and B. S. Meldrum (1988) Epilepsy and excitatory amino acid antagonists. In Excitatory Amino Acids in Heallh and Disease, D. Lodge, ed., pp. 353-378, Wiley, Chichester, UK.

Racine, R. J., N. W. Milgram, and S. Hafner (1983) Long-term potentiation phenomena in rat limbic forebrain. Brain Res. 260: 217231.

Rawlins, J. N. P. (1985) Associations across time: The hippocampus as a temporary memory store. Behav. Brain Sci. 8: 479-528.

Reymann, K. G., H. Ruthrich, L. Lindenau, T. Ott, and H.-J. Matthies (1982) Monosynaptic activation of the hippocampus as a conditioned stimulus: Behavioural effects. Physiol. Behav. 29: 1007-1012.
Reynolds, E. T. (1983) Mental effects of antiepileptic medication: A review. Epilepsia 24 (Suppl. 2): S85-S95.

Rolls, E. T. (1987) Functions of neuronal networks in the hippocampus and neocortex in memory. In Neural Models of Plasticity: Theoretical and Empirical Approaches, J. H. Byrne and W. D. Berry, eds., pp. 50-67, Academic, New York.

Routtenberg, A., D. M. Lovinger, and O. Steward (1985) Selective increase in phosphorylation of a $47 \mathrm{kDa}$ protein $(\mathrm{F} 1)$ directly related to long-term potentiation. Behav. Neural Biol. 43: 3-11.

Salt, T. E. (1986) Mediation of thalamic sensory input by both NMDA receptors and non-NMDA receptors. Nature 322; 263-265.

Simon, R. P., J. H. Swan, T. Griffiths, and B. S. Meldrum (1984) $\mathrm{N}$-methyl-D-aspartate receptor blockade prevents ischaemic brain damage. Science 226: 850-852.

Singer, W. (1987) Activity-dependent self-organisation of synaptic connections as a substrate of learning. In The Neural and Molecular Bases of Learning. J.-P. Changeux and M. Konishi, eds., pp. 301336, Wiley, Chichester, UK.

Skelton, R. W., J. J. Miller, and A. G. Phillips (1985) Long-term potentiation facilitates behavioural responding to single-pulse stimulation of the perforant path. Behav. Neurosci. 99: 603-620.

Snell, L. D., and K. M. Johnson (1988) Phencyclidine: Behavioural correlates of NMDA antagonism. In Excitatory Amino Acids in Health and Disease, pp. 261-274, Wiley, Chichester, UK.

Squire, L. R. (1987) Memory and Brain, Oxford U.P., New York.

Squire, L. R., and S. Zola-Morgan (1983) The neurology of memory: The case for correspondence between the findings for man and nonhuman primates. In The Physiological Basis of Memory, J. A. Deutsch, ed., pp. 200-268, Academic, New York.

Sutherland, R. J., and R. H. Dyck (1984) Place navigation by rats in a swimming pool. Can. J. Psychol. 38: 322-347.

Sutherland, R. J., I. Q. Whishaw, and B. Kolb (1983) A behavioural analysis of spatial localisation following electrolytic, kainate- or colchicine-induced damage to the hippocampal formation in the rat. Behav. Brain Res. 7: 133-153.

Sutherland, R. J., I. Q. Whishaw, and B. Kolb (1988) Contributions of cingulate cortex to two forms of spatial learning and memory. J. Neurosci. 8: 1863-1872.

Swanson, L. W., T. J. Teyler, and R. F. Thompson (1982) Hippocampal long-term potentiation: Mechanisms and implications for memory. Neurosci. Res. Prog. Bull. 20: 613-769.

Teyler, T. J., and P. DiScenna (1986) The hippocampal memory indexing theory. Behav. Neurosci. 100: 147-154.

Thompson, P., and M. R. Trimble (1982) Anticonvulsant drugs and cognitive functions. Epilepsia 23: 531-544.

Thompson, R. (1976) Stereotaxic mapping of brainstem areas critical for memory of visual discrimination habits in the rat. Physiol. Psychol. 4: 1-10.

Thomson, A. M., D. C. West, and D. Lodge (1985) A N-methyl-Daspartate receptor-mediated synapse in rat cerebral cortex: A site of action of ketamine? Nature 313: 479-481.

Tonkiss, J., R. G. M. Morris, and J. N. P. Rawlins (1988) Intraventricular infusion of the NMDA antagonist AP5 impairs DRL performance in the rat. Exp. Brain Res. 73: 181-188.

Turski, L., M. Schwarz, W. A. Turski, T. Klockgether, K.-H. Sontag, and J. H. Collins (1985) Muscle-relaxant action of excitatory amino acid antagonists. Neurosci. Lett. 53: 321-326.

Urquhart, J., J. W. Fara, and K. L. Willis (1984) Rate-controlled delivery systems in drug and hormone research. Annu. Rev. Pharmacol. Toxicol. 24: 199-236.

Watkins, J. C., and R. H. Evans (1981) Excitatory amino acid neurotransmitters. Annu. Rev. Pharmacol. Toxicol. 21: 165-204.

Watkins, J. C., and H. O. Olverman (1987) Agonists and antagonists for excitatory amino acid receptors. Trends Neurosci. 17: 265-272.

Weiskrantz, L. (1982) Comparative aspects of studies of amnesia. Philos. Trans. R. Soc. Lond. (Biol.) 298: 97-109.

Whishaw, I. Q. (1985) Cholinergic receptor blockade in the rat impairs locale but not taxon strategies for place-navigation in a swimmingpool. Behav. Neurosci. 99: 979-1005.

Whishaw, I. Q., W. T. O'Connor, and S. B. Dunnett (1985) Disruption of central cholinergic systems in the rat by basal forebrain lesions or atropine: Effects on feeding, sensorimotor behaviour, locomotor activity and spatial navigation. Behav. Brain Res. 17: 103-115.

Wigstrom, H., B. Gustafsson, Y.-Y. Huang, and W. C. Abraham (1986) 
Hippocampal long-term potentiation is induced by pairing single afferent volleys with intracellularly injected depolarising current pulses. Acta Physiol. Scand. 126: 317-319.

Willshaw, D. J., O. Bunemann, and C. Longuet-Higgens (1969) Nonholographic associative memory. Nature 222: 960-962.
Wong, E. H., J. A. Kemp, T. Priestley, A. R. Knight, and L. L. Iversen (1986) The anticonvulsant MK-801 is a potent N-methyl-D-aspartate antagonist. Proc. Natl. Acad. Sci. USA 83: 7104-7108. 